А. А. Коробков, В. В. Бялт, В. А. Бубирева

ТИПОВЫЕ ОБРАЗЦЫ РОДА ARTEMISIA L. s.1. (ASTERACEAE), ХРАНЯЩИЕСЯ В ГЕРБАРИИ САНКТ-ПЕТЕРБУРГСКОГО ГОСУДАРСТВЕННОГО УНИВЕРСИТЕТА (LECВ)

\begin{abstract}
Статья продолжает серию публикаций, посвященных историческим коллекциям и коллекции типовых гербарных образцов, хранящимся в Гербарии кафедры ботаники СанктПетербургского государственного университета (LECB). В результате критического изучения рода Artemisia L. s. l. (Asteraceae) в Гербарии LECB выявлено 134 типовых образца для 93 таксонов из родов Absinthium Mill. и Artemisia L. (43 вида, 1 подвид, 48 разновидностей и 1 форма). В коллекции представлены типы (синтипы и изотипы) таксонов, описанных К. Вильденовым (C. Willdenow), М. Биберштейном (M.von Bieberstein), К. Ледебуром (C. Ledebour), В. Бессером (W.Besser), А. Бунге (A. Bunge), И.М.Крашенинниковым и некоторыми другими из Сибири, Центральной Азии, Ирана, Кавказа, Крыма и Гавайских островов в Океании. Библиогр. 22 назв.

Ключевые слова: систематика, типовые образцы, СПбГУ, Гербарий LECB, Artemisia, Asteraceae.
\end{abstract}

\title{
A. A. Korobkov ${ }^{1}$, V.V.Byalt ${ }^{1}$, V.A.Bubyreva ${ }^{2}$
}

\section{TYPICAL SPECIMENS OF GENUS ARTEMISIA L. S. I. (ASTERACEAE) KEPT IN THE HERBARIUM OF ST. PETERSBURG STATE UNIVERSITY (LECB)}

${ }^{1}$ V. L. Komarov Botanical Institute RAS, 2, ul. Professora Popova, St. Petersburg, 197376, Russian Federation; AKorobkov@binran.ru, byalt66@mail.ru, VByalt@binran.ru

2 St. Petersburg State University, 199034, St. Petersburg, Universitetskaya nab., 7/9; bubyreva@mail.ru

This article continues a series of publications devoted to the historical collections and collections of type herbarium specimens stored in the Herbarium of Department of Botany, St. Petersburg state University (SPbSU) (LECB). As a result of critical study of the genus Artemisia L. s.l. (Asteraceae) in the Herbarium LECB 134 type specimens for 93 taxa of the genera Absinthium Mill. and Artemisia L. (43 species, 1 subspecies, 48 varieties and 1 form) are identified. In the collection the types (syntype and isotypes) for taxa described by C.Willdenow, M.von Bieberstein, C.Ledebour, W. Besser, A. Bunge, I.M. Krasheninnikov and some others from Siberia, Central Asia, Iran, Caucasus, Crimea and even the Hawaiian Islands in Oceania are presented. Refs 22.

Keywords: systematics, type specimens, St. Petersbug State University, Herbarium LECB, Artemisia, Asteraceae.

Статья продолжает серию публикаций об исторических коллекциях и коллекции типовых гербарных образцов, хранящихся в Гербарии кафедры ботаники Санкт-Петербургского государственного университета (СПбГУ) (LECB) [1-12]. В результате критического изучения рода Artemisia L.s.l. (сем. Asteraceae) в Гербарии LECB выявлено 134 типовых образца для 93 таксонов из родов Absinthium Mill. и Artemisia L. (43 вида, 1 подвид, 48 разновидностей и 1 форма). В коллекции представлены типы (синтипы и изотипы) таксонов, описанных К. Вильденовым (C. Willdenow), М.Биберштейном (M.von Bieberstein), К. Ледебуром (C.Ledebour),

А.А. Коробков (AKorobkov@binran.ru), В.В.Бялт (byalt66@mail.ru, VByalt@binran.ru): Ботанический институт им. В. Л. Комарова РАН, Российская Федерация, 197376, Санкт-Петербург, ул. Профессора Попова, 2; В. А. Бубырева (bubyreva@mail.ru): Санкт-Петербургский государственный университет, Российская Федерация, 199034, Санкт-Петербург, Университетская наб., 7/9.

(c) Санкт-Петербургский государственный университет, 2016 
B. Бессером (W. Besser), А. Бунге (A. Bunge), И. М. Крашенинниковым и некоторыми другими ботаниками из разных районов Сибири, Центральной Азии, Ирана, Кавказа, Крыма и Гавайских островов в Океании.

Полынь (Artemisia L.s.l.) - род травянистых, полукустарничковых или полукустарниковых растений семейства Астровые (Asteraceae).

Ботаническое латинское название «Artemisia» образовано от древнегреческого

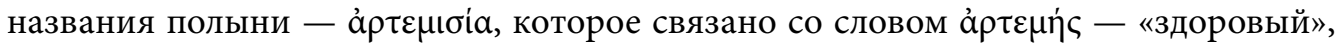

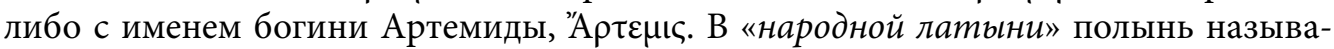
ли absinthium, что также является заимствованием из древнегреческого, á $\psi \mathbf{i} v \theta \imath \mathrm{v}$, которое, вероятно, заимствовано из персидского. Оба латинских слова встречаются в названии Полыни горькой, Artemisia absinthium L. (https://ru.wikipedia. org/wiki/Полынь; [13]). Это же слово (absinthium) послужило названием для рода Absinthium Mill.

Полыни распространены по всему северному полушарию, в умеренном поясе Евразии, в Северной и Южной Африке, Северной Америке. На территории России и сопредельных стран отмечено около 180 видов, встречающихся почти повсеместно. Наиболее распространены полыни в степях и пустынях Казахстана, Средней Азии, в Закавказье, на Юго-Востоке европейской России и Украине.

Очень важную роль в формировании современного растительного покрова полыни играют в степных и пустынных районах Казахстана, в горных степях и высокогорных пустынях Средней Азии. Здесь представлены огромные почти чистые заросли, чаще всего состоящие из полукустарничковых видов подрода Seriphidium. На юге и востоке европейской России, в Северном Казахстане широко распространены «полынные степи», в которых доминирующую роль играют Artemisia pauciflora, A. lerchiana, A. austriaca и псаммофильные виды подрода Dracunculus.

Полыни - дву- и многолетние (реже однолетние) травы, полукустарнички и полукустарники. Стебли обыкновенно прямые, высотой 3-150 см, с толстым деревянистым корнем. Все растение имеет более или менее густое беловатое или сероватое опушение, часто растения серебристые или войлочные. Листья пальчатоили перисто-раздельные, очередные, рассеченные, реже цельные и цельнокрайные, конечные доли небольшие ланцетные или нитевидные. Нижние листья крупные, чаще на длинных черешках, средние и верхние - мельче, менее рассечены, обычно сидячие. Цветки чрезвычайно мелкие, чаще желтые, иногда красноватые или фиолетовые, собраны в мелкие соцветия яйцевидные, чашевидные или почти шаровидные корзинки 1,5-10 мм в диаметре с черепитчатыми листочками обертки. Соцветия состоят из тончайших трубчатых обоеполых цветков, причем краевые нитевидные, и однополых пестичных; все соцветие окружено черепитчатой оберткой. Корзинки собраны в длинные кисти, колосья или метелки. У одних видов в корзинках 1 ряд пестичных трубчатых краевых цветков и более многочисленные обоеполые цветки диска (подрод Artemisia); у других - цветки диска тычиночные (подрод Dracunculus) или все цветки в корзинках - обоеполые, трубчатые (подрод Seriphidium). Плоды - гладкие, мелкие семянки (1,5-2 мм длиной), без паппуса, часто ослизняющиеся.

Ниже приведен список всех выявленных к настоящему времени (к концу 2015 г.) аутентичных образцов из родов Artemisia и Absinthium (=Artemisia s. 1.), хранящихся в коллекции типов Гербария СПбГУ (LECB). 
В коллекции представлены типы (синтипы и изотипы) таксонов, описанных К. Вильденовым (C. Willdenow, 1765-1812), М.Биберштейном (M. von Bieberstein, 1768-1826), К. Ледебуром (C. Ledebour, 1786-1851), В. Бессером (W. G. Besser, 17741842), А.Бунге (A. Bunge, 1803-1890), И.М.Крашенинниковым (1884-1947) и др. из Сибири, Центральной Азии, Ирана, Кавказа, Крыма и Гавайских островов в Океании. Особенно много образцов, относящихся к таксонам, описанным Виллибальдом Бессером - одним из первых крупных монографов рода полынь (Artemisia).

В аннотированном списке названия типифицируемых таксонов расположены в алфавитном порядке. Для каждого названия приведена номенклатурная цитата (в ряде случаев указывается принятое в настоящее время название растения), категория типа, полный текст гербарной этикетки (в квадратных скобках приводятся наши дополнения к этикетке), цитата из протолога (первоописания); в необходимых случаях даются примечания. В круглых скобках приводятся акронимы Гербариев, в которых выявлены типовые образцы данных таксонов, восклицательный знак означает, что мы смогли ознакомиться с изображениями этих образцов в Интернете (на различных сайтах, см.: http://plants.jstor.org/search?t=1989; http:// coldb.mnhn.fr/colweb/form.do? model=SONNERAT.wwwsonnerat.wwwsonnerat.wwwsonnerat; http://apps.kew.org/herbcat/gotoSearchPage.do; http://herbarium.univie.ac.at/ database/search.php и мн. др.).

В связи с этим у нас нет особых сомнений в подлинности изотипов и синтипов, хранящихся в гербарии СПбГУ (LECB). Расшифровки акронимов гербариев можно посмотреть в Index Herbariorum [14] или на сайте Index Herbariorum (http:// sweetgum.nybg.org/ih/).

Цифры при акрониме LECB [«LECB: 1611!»] обозначают номера, под которыми их электронные изображения и данные этикеток будут размещены на сайте Virtual Herbaria Венского университета (http://herbarium.univie.ac.at/database/search.php).

Absinthium divaricatum Fisch. ex Besser, 1829, Bull. Soc. Imp. Naturalistes Moscou, 1, 2: 263. = Artemisia abrothanum L.

Syntypus?: Сибирь, «Artemisia procera W.Artemisia anethifolia Fisch. Herb. Ed. a Lindemann»(LECB: 3712!).

По протологу: «A. divaricatum (Fisch. herb. Bess. Monogr. ined.) ... A. anethifolia Stechm. p. 29. n. 25 ex autopsia speciminis Gméliniani in herb. Acad. imp. Sc. quod iconi Fl. Sib. II.p. 119. n. 103 t. 54 typo inserviit. (v. s. sp.)».

Absinthium frigidum (Willd.) Besser var. gmelinianum Besser, 1829, Bull. Soc. Imp. Naturalistes Moscou, 1, 2: 254. = Artemisia frigida L.

Syntypus: Зап. Сибирь, Алтай, «Artemisia frigida W.1803, Sibir. alt. s.d., [fl.], Dr. Gebler» Ledeb. flor. ross. 515-80» (LECB: 3713!).

Syntypus: Сибирь, «Artemisia frigida W. $\delta$. Gmeliniana mihi In rupibus ad Solocutmon [?], [s.d.], [fr.], Herb. W. Besser» (LECB: 3714!).

По протологу: « $\delta$. Gmelinianum (Bess. Monogr. ined.) ... Huc Gmel. Fl. Sib. II.p. 128 111. t. 62. ex autopsia speciminum ab ipso autore in herb. Acad. Imp. Sc. Petrop. A Jeniseo orientem versus et meridiem in transbaicalenses usque regiones. E Krasnojarsk, in Herb. Stev. In montibus altaicis secundariis, Dr. Gebler. A. jeniseensis Spr. Syst. Veg. III.p. 469 n. 27 et Willd. herb. ex Adnotationibus Stev. in herbarium Willdenowianum». 
Absinthium moxa Besser, 1829, Bull. Soc. Imp. Naturalistes Moscou, 1, 2: 228.

Syntypus?: Вост. Азия, Китай, «Artemisia moxa, sine loco, [s.d.], veg., s. coll. Еx Herbarium H. G. Bongardii» (LECB: 3715!).

По протологу: «Moxa (mihi Monogr. ined. c. icone) ... In China, (v. c. s. in herbario Prescottii)».

Absinthium pedunculare Stev. 1813, Mém. Soc. Imp. Naturalistes Moscou, 4: 63.

Syntypi (2)?: "Artemisia peduncularis MB. Caucas., Alp. Schadagh, [s.d.], sine coll. [manus Steveni]. Ex Herbarium H. G. Bongardii» (LECB: 3716-3717!).

По протологу: «In saxis Caucasi orientalis subalpinis versus fontes torrentis Chodjal. Junio».

Absinthium rupestre (L.) Schrank var. thuringiacum Besser - Bull. Soc. Imp. Naturalistes Moscou 1(8): 248. $1829=$ Artemisia rupestris L.

Syntypus: Центр. Европа, Германия, «Artemisia rupestris L. var. thuringiaca Wallr. Herb. Ed. a Lindemann», "41. Artemisia rupestris L.cf. Wallr. sched. crit. p. 468. t. IV. Auf salsigem kalkboden bei Borksleben in Thüringen. s.d., [fl.], Wallroth. Exs Reichb. n. 41» (LECB: 3808!).

Прим. Синтип смонтирован на одном листе с нетиповым образцом Питтони «Artemisia rupestris L. Suansson Bonaleben in Thüringien Autumno Oertel, s.d., [fl.], Ex herbario J. C. Equitis Pittoni a Dannenfeldt».

По протологу: "Ab ipsissimo Wallrothio in Herb. MB. Fischer, Lang. Schultes etc. - A. grandiflora Hoffm. Fl. Germ.».

Artemisia absinthium L. var. bungeana Lindem. nom. nud.? = Artemisia absinthium L.

Syntypus?: Вост. Европа, Украина, «Artemisia Absinthium L. $\beta$. Bungeana Lindem. Cherson pr. Elisbethgrad, 1 VIII 1865? [fl.], Herb. Ed. a Lindemann», «Artemisia Absinthium L. $\beta$. bungeana mihi / $\beta$ simplex Bunge Herb. Ed. a Lindemann» (LECB: 3718!).

Artemisia afra Jacq. ex Willd. 1803, Sp. Pl., ed. 4, 3, 3: 1820.

Syntypus?: Юж. Африка, Зап. Капская пров., «Artemisia affra s.d., [fl.], Ex Herbarium H. G. Bongardii» (LECB: 3719!).

По протологу: «Artemisia afra. A. frutescens, foliis bipinnatifidis subtus tomentolis, laciniis lanceolatis obtufis, panicula fecunda, floribus nutantibus. W. Artemisia afra. Jacq. Africanischer Beyfus. W. Habitat ad Cap. b. spei? h (v. v.)».

Artemisia alpina Bieb. 1808, Fl. Taur. Cauc. 2: 297, non Pall. ex Willd., 1803. = Artemisia caucasica Willd.

Syntypus?: Центр. Кавказ, Грузия, «Artemisia alpina MB.A.caucasica», «Artemisia lanata DC. Tiflis, s.d., [fl.], M.a Bieberstein. Ex Herbarium H. G. Bongardii» (LECB: 3720 !).

По протологу: «Habitat ip rupestribus apricis Tauriae et Caucasi. Floret Julio, Augusto». 
Artemisia aralensis Krasch. 1936, Список раст. Герб. фл. СССР 10: 104, экс. № 3196.

Isotypus: Ср. Азия, Казахстан, «Artemisia aralensis H. Krasch. n. sp. ... Казахская ACСР.На глинистых местах в степи близ ж.-д. ст. Кара-Чокат. Kazahstania. In steppa locis argilosis prope stationem viae ferreae Kara-Chokat. 26 IX 1908, [fl., fr.], Л.Бубырь. - L. Bubyr. Herbarium Florae URSS n. 3196» (K!, LECB: 2220!, M, S, WIS).

Holotypus: LE.

По протологу: «3196. Artemisia aralensis H. Krasch. n. sp. ... Казахская АССР. На глинистых местах в степи близ ж.-д. ст. Кара-Чокат. Собр. Л. Бубырь. - Kazahstania. In stepplocis argilosis prope stationem viae ferreae Kara-Chokat. Leg. L. Bubyr 1908 IX 26».

Artemisia arctica Less. 1831, Linnaea 6: 213.

Syntypus?: «Artemisia, sine loco, [fl.], Kastalsky [= Chamisso \& Kastalsky]. Ex Herbarium H. G. Bongardii», «Artemisia arctica Less. det. IV 2015, det. Коробков» (LECB: 3722!).

Прим. А.Шамиссо (A. von Chamisso, 1781-1838) и Г. Кастальский (даты жизни неизвестны) вместе участвовали в кругосветной экспедиции О.Е. Коцебу (1815-1818).

Syntypus: «Artemisia, Unalaschka, [s.d.], [fl.], [Chamisso]. Ex Herbarium H. G. Bongardii» (LECB: 3723!).

По протологу: «Artemisia arctica n. sp. Cel. de Chamisso in Unalaschca, ad sinum St Laurentii, ad Cap Espenberg, in insula St Laurentii; Redowski in Kamtschatka».

Artemisia australis Less. 1831, Linnaea 6: 522. = A.eschscholtziana Besser, 1834, Nouv. Mém. Soc. Imp. Naturalistes Moscou, 3: 24.

Syntypus: Океания, США, Гавайские о-ва, «Artemisia Eschscholtziana mihi E Wahu, s.d., [fr.], Mertens», "Artemisia Eschscholtziana Besser. E montibus Wahu, Insula sandwich. XI 1816, [fr.], Eschscholz. Besser [det.]. Herb. Lindemann» (K, LECB: 3760!).

Прим. Также образец является синтипом A. eschscholtziana Besser (см. ниже).

По протологу: "Artemisu australis n. sp. Ill. de Chamisso in O-Wahu Sandvicen$\operatorname{sium}($ v. sp. s. $\infty) »$.

Artemisia austriaca Jacq. var. lamarckiana Besser, 1834, Nouv. Mém. Soc. Imp. Naturalistes Moscou, 3: 49. = Artemisia austriaca Jacq.

Syntypus?: Вост. Европа, Россия, Воронежская обл., «Gov. Woronesch, s.d., [fl], [Chernjaev]» (LECB: 3725!).

Syntypus: "Artemisia austriaca Jacq. $\delta$. orientalis DC.Astrachan, [s.d.], [fl.], Blum. Herb. Ed. a Lindemann», «Astrachan, Ledebour ex pl. Blum» (LECB: 3726!).

По протологу: «є. Lamarkiana (Bess. Monogr. inédit. A. austriaca ß. Lam. Encycl. I.p. 259. A.orientalis.Willd. Spec. pl. III p.1836 n. 47.)».

Artemisia austriaca Jacq. var. pallasiana Besser, 1834, Nouv. Mém. Soc. Imp. Naturalistes Moscou, 3: 49. = Artemisia austriaca Jacq.

Syntypus: «Artemisia austriaca Jacq. $\delta$. Pallasiana Bess. Schmidt. Herb. Lindemann», «Artemisia repens Pall. 1800. Schmidt. Herb. Lindemann» (LECB: 3726!).

Syntypus?: «Artemisia repens Pall. (1800) Herb. Fleischer. XIX. II. 2730.65».

По протологу: «ठ. Pallasiana (Bess. Monogr. inédit. A. repens Pall. in Willd. Spec. pl. III 1840 n. 55.)». 
Artemisia austriaca Jacq. var. szowitziana Besser, 1834, Nouv. Mém. Soc. Imp. Naturalistes Moscou, 3: 50. = Artemisia austriaca Jacq.

Syntypus: Юж. Закавказье, «Artemisia austriaca $\beta$. orientalis. Ararat, [fl.], Szowits $\mathrm{n}$. 23. Ex herbario horti Petropolitani» (LECB: 3727 !).

Syntypus: Южн. Закавказье, Азербайджан, Нахичевань, «Artemisia austriaca $\beta$. orientalis. Nakitschewan, [fl.], Szowits n. 548. Ex herbario horti Petropolitani» (LECB: 3728 !).

По протологу: «ฤ. Szowitziana (Bess. Monogr. inédit.)».

Artemisia balchanorum Krasch. 1936, Список раст. Герб. фл. СССР 10 : 104, экс. № 3197.

Isotypi (2): Ср. Азия, Туркмения, "Artemisia balchanorum H. Krasch. sp. n. ... Туркменская ССР. Б. Балханы близ колодца Патма. - Asia media. Turcomania. Montes B. Balchany, prope puteum Patma. VIII 1928, [fr.], Е. Бобров / E. Bobrov. Herbarium Florae URSS n. 3197» (K!, LE, LECB: 2221-2222!, M, S).

По протологу: «3197. Artemisia balchanorum H.Krasch. sp. n. ... Туркменская ССР.Б.Балханы близ колодца Патма. Собр. Е. Бобров. - Asia media. Turcomania. Montes B. Balchany, prope puteum Patma. Leg. E. Bobrov. 1928 VIII».

Artemisia baldshuanica Krasch. \& Zapr. 1937, Trudy Bot. Inst. Akad. Nauk S. S. S. R., Ser. 1, Fl. Sist. Vyssh. Rast. 3: 351.

Isotypus: Ср. Азия, Таджикистан, «Artemisia baldshuanica Krasch. et Zapr. Склон долины р. Ях-су, близь к-ка Панжерок, высота 1600 м, 19 IX 1931, [fr.], Ф.Запрягаев. Herbarium Instituti Botanici Acad. Sc. URSS. Копия» (LECB: 2223!).

По протологу: «Artemisia baldshuanica H. Krasch. et Zapr. sp. n. ... Typus. Asia média, Tadzhikistania in valle f lum. Jach-su, prope pagum Piandjirion, 19 IX 1931, № 184 (Zaprjagaev).... Artemisia baldshuanica впервые была собрана Липским 22 VI 1896 г. в Денавском районе, вблизи кишлака Догора-Чакоб. Значительно позже ее собрал Гончаров (2 IX 1931) на склонах горы Ходжа-Мастан близ родника ЗаранБулак (Локай-Таджикский р-н) и (13 IX 1931 г.) в горах Ак-тау, возле родника Заран-Булак (Кабадианский р-н) и, наконец, Запрягаев в 1931 г. (19 IX) в долине реки Як-су, около кишлака Пянджерион (Ховалингский р-н), 13 VI 32 в предгорьях хребта Люличан в окр. кишлака Маслык (Пархарский р-н) и в 1933 г. на коренном берегу p. Варзоб, вблизи Сталинабада. Кроме того A. baldshuanica собирал С.Н. Кудряшев, который приводит ее в своей работе “Дикорастущие эфиро-масличные растения центральной части Гиссарского хребта”, под названием A. maritima» [15].

Artemisia borealis Pall. var. ledebourii Besser, 1835, Bull. Soc. Imp. Naturalistes Moscou, 8: 85.

Syntypus: «Artemisia violacea Ledeb. A. borealis Pall. $\delta$. Ledebouri Bess. Herb. Fleischer. XIX. II. 2730.63» (LECB: 3730!).

По протологу: «ठ. Ledebouri (Bess. Monogr, ined.) ... A. violacea Ledeb. Decad. plant, in Mémoires de l'Académie Impér. des Sciences de St. Pétersbourg V.p. 567, Flor. Altaic. IV p. $78^{\star}$ ). Icon. pl. Flor. Boss. alt. illustr. t. 475. In ripis humidiusculis fluvii Kergon Bunge (Ledeb. 1. c). In terra Tschuktschorum ad sinum S. Laurentii et in insula St. 
Laurentii maris Kamtschatensis Eschsch. In Kamtschatka Tiles. (Ledeb.) ... Kamtschatka Esch. E terris arcticis Sibiriae Adams (A. Gmelini non Stechm. herb. Stev.) ... Katschatka Esch. ... In montibus scopulosis Americ. septent. orient. Drummond. (Hook. herb.). - ... In littoribus arcticis Dr. Richardson (Hook. herb.)».

Artemisia borealis Pall. var. mertensii Besser, 1835, Bull. Soc. Imp. Naturalistes Moscou, 8: 87.

Syntypus: Сев.-Вост. Азия, Россия, Чукотка, «Artem. Senjaviniana Bess. Ad fret. Senjavin, s.d., fl., Mertens. Ex Herbarium H. G. Bongardii» (LECB!).

По протологу: « $\xi$. Mertensii (Bess. Monogr. ined. e. icon.) ... E Koraginsk Dr. Mertens (herb. Acad. Imp. Sc.) ... Ad fretum Senjavin ${ }^{\star}$ ). Dr. Mertens. ... E Koraginsk Dr. Mertens (herb. Acad. Imp. Sc). ... Specimina Kamtschatensia a Langsdortio et ex Ischiga a Kruhsio (A. Stelleri Stev. Herb. Fisch.) lia adhuc specimina e Kamtschatka a Dre. Mertensio (herb. Acad. Imp. Sc.), Merkio (herb. Fisch.) Chorisio (herb. Acad. Imp. Sc.) $\left.\ldots{ }^{\star}\right)$ Hoc est sub $64^{\circ}$ lat. bor. inter fretum Beringii et Kamtschatka m prope ostium fluvii Anadyr, formatur a terra firm a et duabus insulis in magno sinu locatis ... Kamtschatka Esch. America rossica Ledebour. - e, Eadem ac var. ci e Kamtschatka a Dr. Mertensio ... E. Kamtschatka ? herb. Amman. (herb. Acad. Imp. Sc.) - ... In Kamtschatka (herb. Lindl.) Dr. Mertens et e portu Petripauli Kastalsky (herb. Acad. Imp. Sc.)».

Artemisia borealis Pall. var. purshii Besser, 1833, Fl. Bor.-Amer. (Hooker) 1: 326.

Syntypus: Сев. Америка, "A.borealis a. Purshii mihi A.spithamea Pursh var. $\varepsilon . »$, «Artemisia borealis Pall. a. purshii Besser Sin. St. Laurent., s.d., fl., Eschscholz. Herb. Lindemann 2730.B3» (LECB: 3729!).

По протологу: «а. Purshii ... A. spithamaea. Pursh, Fl. Am. v. 2. p. 522 ...».

Artemisia borealis Pall. var. schanginii Besser, 1835, Bull. Soc. Imp. Naturalistes Moscou, 8: 90.

Syntypus: Зап. Сибирь, Алтай, «Artemisia violacea Ledeb. / ๆ. Schangini Bess. Flor. altaica, s.d., fl., [Ledebour] Herbar. Th. Bienert. Ex Herbarium H. G. Bongardii» (LECB!).

По протологу: « a Wormskioldio nomine A. borealis (herb. Prof. Koch.) ... E Sibiria orientali Schangin (A. vermiculata Schang. herb, in herb. Fisch.). - ... Ad Fluvium Tschuja regionis alt. A. violaceae Fl. Alt. var. G. A. Meyer - in lit.».

Artemisia caespitosa Ledeb. VII-XII 1833, Fl. Altaic. 4: 80.

Syntypus: «Artemisia caespitosa Ledeb. Sibir, [s.d.], [fr.], Ledeb. Ex Herbarium H. G. Bongardii» (LECB: 3731!).

По протологу: «A. caespitosa. Ledeb. Ic. pl. Fl. ross. alt. illustr. t. 472. Hab. in limososalsis sterilissimis deserti editi ad fl. Tschuja extensi (B.). Fl. Jul.».

Artemisia campestris L. var. canescens Boiss. 1875, Fl. Orient. 3: 363.

Syntypus: Кавказ, «Artemisia inodora Caucas. s.d., [fl.], Hohenacker. Ex Herbarium H. G. Bongardii» (LECB!). 
По протологу: « $\beta$. canescens. - Plus minus adpresse canescens, foliorum laciniae saepe crassiores. - A. inodora M. B. Taur. Cauc. II, p.295. - A. Marschalliana Spr. Syst. III, p. 496. - A. commutata Bess. quoad locum Caucasicum. Hab. in incultis et campestribus Tauriae, prov. Caucasicarum et prsesertim Transcaucasiae (M. B. Hoh!), Armeniae Rossicae (Szov!), Turcicae ad lacum Van (Ky. 465!), Persiae borealis (Buhse), Affghaniae (Griff!).».

Artemisia campestris L.var. gmeliniana Besser, 1835, Bull. Soc. Imp. Naturalistes Moscou, 8: 45.= A. marschalliana Spreng. V 2015 Коробков.

Syntypus: Вост. Европа, Крымский п-ов, «Tauria, [s.d.], [fl.], sine coll.», «Artemisia inodora MB. Artemisia campestris L. d. Gmeliniana Bess. Tauria, Ledebour. [s.d.], [fl.], Herb. Ed. a Lindemann» (LECB: 3736!).

Syntypus: Вост. Европа, Крымский п-ов, «Таuria» (LECB: 3732!).

Syntypus: Вост. Европа, культ., «Artemisia campestris L. $\delta$. Gmeliniana Besser Hort. Dorp., s.d., [fl.], Herb. Lindemann», «E seminibus sine nomine a Ledeburio lectis culta Dorpati (herb. Lindem.) Besser De Dracunculis 1834 p. 44» (LECB: 3733!).

Syntypus: Вост. Европа, Украина, «Artemisia monogyna ? Ekaterinoslaw, [s.d.], [fl.], Haupt» (LECB!).

Syntypus?: Вост. Европа, «Artemisia albida W. herb. Herb. Fleischer XIX. II. 2730.99» (LECB!).

Syntypus: Вост. Европа, Россия, Ростовская обл., «Artemisia Marschalliana Spreng. (A. inodora MB.) Rupes stanitzae Grusekewka ad Tanain, [s.d.], [fl.], H[enning?].», «Artemisia Marschalliana Spr. Tanais. Herb. Lindemann 2730.105» (LECB: 3735!).

Syntypus: Вост. Европа, Россия, Ростовская обл., «Artemisia campestris L. (1737) $\gamma$ Gmeliniana Bess. Tanais, [s.d.], Henning Ledeb. flor. ross.», «Rupes ad Tanain», «Artemisia maritima Gmeliniana Spr. 1826 Herb. Fleischer XIX. II. 2730.105» (LECB: 3734!).

По протологу: «ठ. Gmeliniana Bess. Monogr. ined. c. icon. A.inodora et infirma Gmel. jun. (herb. Acad. Imp. sc.) A. inodora MB. Flora Taur. - Cauc. II p. 295 Suppl. p. 565 ... In desertis caspicis Tauscher (herb. Fisch.) in deserto cumano Ledeb. (herb. Lang.) Odessae Szowitz Ekaterinoslaviae Haupt (herb. MB.) in Volhynia, circa Nowy Sewersk Dr. Mertens (herb. MB), in District. Pinsk Lithuaniae Wolfg. ad mare balticum D. Fleischer, Mag. Lindemann. E seminibus sine nomine a Ledebonrio lectis culta Dorpati (herb. Lindem.) et Cremeneci. E seminibus Kamtschatensibns sine nomine a Fischero communicatis, culta Cremeneci; nomine denique A. harealis Desf. (nequaquam confundenda cum A. boreali Pall.) Cat. edit. 3. Addit (1832) p. 445 culta Parisiis et exinde in aliis hortis nec non in Cremenecensi. - b. pericliniis subnudis erectis minoribus. In Caucaso MB. In Tauria MB. Stev. In desertis caspicis Tauscher (herb. Fisch.) ad Tanain Hermann Herb. Presc.) Stev. Circa Odessam Andrz. Szowitz. Ad Liguiez MB. Prope Molotschna ad Barysthenem in foriorem Stev. In agro Sareptano ad Wolgam Wunderlich (herb. MB.) Ad lacum Inderiensem Karelin (Herb. Imp. Acad. Sc.) In Podolia occidentali Andrz. Cremeneci. Vilnae in Lithuania Wolfg. Ad mare balticum Lindem. In campis altaicis Ledeb. circa Tobolsk (herb. MB.) calathidiis erectis majoribus Charkoviae Tschern. (herb Univ. Chark.) calathidiis cernuis A. lednicensis Rochel herb. (Spreng Syst. Veg. III p. 45 n 91) - calathidiis subglobosis. In Tauria Haupt (herb. MB.) In Volhynia Andrzejouski. - c. pericliniis midis In Caucaso Stev. In Tauria (herb. Fleisch.) In regione altaica secundum Ledeb. Flor. Altaica l. c.». 
Artemisia campestris L.var. linneana Besser, 1835, Bull. Soc. Imp. Naturalistes Moscou, 8: 42.

Syntypi (2): Вост. Европа, Крымский п-ов, «Artemisia campestris L. a. Linneana Bess. Drpt. [= Dorpat], s.d., [fl.], sine coll.», «Artemisia campestris L. Hb. Fleischer», "Artemisia campestris L. (1753) a. Linneana Bess. (1835) Herb. Lindemann» (LECB: 3739 !).

Прим. = A. sosnovskyi Krasch. \& Novopokr. V 2015, опр. Коробков.

Syntypi (2): Вост. Европа, Крымский п-ов, «Artemisia campestris L.. L. Linneana Bess. Tauria, s.d., [fl.], Ledebour», "Artemisia campestris L. (1753) a. Linneana Bess. (1835) Ledeb. fl. ross. 313-14. Herb. Ed. a Lindemann» (LECB: 3740-3741!).

Прим. = A. marschalliana Spreng. V 2015, опр. Коробков.

Syntypus: Кавказ, «Artemisia inodora MB. (1808) Caucasus, [s.d.], [fr.], [Hohenacker?]», «Artemisia campestris L. a Linneana Bess. a. calathidiiis racemosis cernuis. Herb. Ed. Lindeman» (LECB: 3738!).

Прим. $=$ A.cf. sosnovskyi Krasch. \& Novopokr. V 2015, опр. Коробков.

По протологу: «а. Linnaeana (Bess. Monogr. inédit. A. campestris Linn. Flor. suecica n. 732. Wahlenb. Fl. Suec. II. p. 510 n. $\left.904^{\star}\right)$... Ad pedem montis Ararat Szowitz, ad s. Severum in Hispania Dufour (herb. Schultes) in Austria (Herb. Schiverek) Bellaqueae prope Parisios (Gay herb.) in Volhynia circa Bialystok (inter Volkhyniam et Lithuaniam versus occidentem) Hortul. Piper. Circa Twer (sub $57^{\circ}$ lat. bor.) Tschern. (herb. Univ. Imp. Chark.) in Suecia (Stev.) Petropoli Trin. (herb. Stev.) Tschern. (Herb. Univ. Chark.). Adest adhuc specimen a Gmelino juniore lectum sine indicatione loci ... In Galicia, Silesia, (Günther Herb.) Pragae in Bohemia Kostelecky (herb. Lang.) in Volhynia, Varsaviae (Schubert herb.). c calathidiis spicatis ovatis 1-1 1/4" caulibus erectis, foliis glabris, Odessae Stev., in Transylvania (ex nomine A.transylvaniae, sub quo specimen est a. d. Roemero communicatum in herb. Fischeri) Pesthini in Hungaria (herb. Rochel.) Circa Kieban et Antonin Volhyniae Hortul. Witrell. d. calathidiis spicatis, ovoideis 1'", nitidis caule erecto foliis incanis. In Iberia Hohenaker (herb. Univ. Chark.). Hoc est specimen omnino intermedium inter A.campestrem et inodoram $\mathrm{MB}$; calathidiis etenim prioris et foliis alterius».

Artemisia campestris L.var. meyeriana Besser, 1835, Bull. Soc. Imp. Naturalistes Moscou, 8: 47.

Syntypus: Кавказ, "Artemisia inodora MB./ Artemisia campestris L.. Meyeriana Besser (1835), Caucasus, Hohenacker s.d., [fl.], Herb. Lindemann» (LECB: 3742!).

Прим. = A. marschalliana Spreng. V 2015, опр. Коробков.

По протологу: «ع. Meyeriana (Bess. Monogr. inédit. A. inodora G. A. Meyer Enumeralio planta rum ex itinere caucasico-caspico etc. p. $73^{\star}$ ) ... Ad Nakitschiwan in valle Koschadara provinciae Karabagh Szowitz. In Caucaso Stev. C. A. Meyer, Kalennitzchenkof; (Herb. Univ. Chark.) Inter Taganrog et Marienpol Tscbern, (idem herb. 1 - b. subnuda, calatbidiis longe pedanculatis. Pestini (A.campestris var. Rochel herb.) In Austria Schivéret - c. subcanescens 9 calathidiis spicatis, paniculatis, panicula stricta Charkoviae Tschern. - calathidiis dense spicatis, paniculatis, panicula stricta Charkoviae, a. patente. In Hungaria (A.lednicensis Roch, herb.) e monte Bogdo ad Wolgam Hermann (herb. Prescott) In Volhynia André. Orenburgi Karelin (herb. Univ. Charkov.) In Gampis Altaicis C.A. Meyer». 
Artemisia campestris L. var. steveniana Besser, 1835, Bull. Soc. Imp. Naturalistes Moscou, 8: 44. = A. marschalliana Spreng. (V 2015, опр. Коробков).

Syntypus?: Вост. Европа, Россия, Астраханская обл., "Artemisia inodora MB. Artemisia campestris L. $\gamma$. Steveniana Bess. Astrachan, s.d., [fl.], sine coll. Herb. Lindemann» «Astrachan» (LECB: 3743!).

Syntypus: Вост. Европа, Украина, «Artemisia inodora MB. 1808 Artemisia campestris L. $\gamma$. inodora Herd. Volhynia, s.d., [fl.], Besser Herb. Ed. a Lindemann», "Artemisia inodora MB. 1808 Herb. Fleischer 2730.105» (LECB: 3745!).

Syntypus: Вост. Европа, Украина, "Artemisia inodora MB. Artemisia campestris $\gamma$. inodora Herd. Charcov, s.d., [fl.], Al. voss», "Artemisia inodora MB. Artemisia campestris $\beta$. Steveniana Bess. 1835 Ledeb. flor. ross. 515-15» (LECB: 3744!).

По протологу: « $\gamma$. Steveniana (Bess. Monogr. ined. A.campestris et inodora herb rossic.) ... In Caucaso et Tauria MB. ad Wolgam Stev. ad Tanain MB. in Hungaria (A. hermaphrodita Kit. in Herb. Acad. Imp. Sc.) Charkoviae Tschern. (Herb. Univ. Chark.) Wladimiriae et Cremeneci in Volhynia, Kioviae MB. In district. Ostrogorsk et Bobrow Gub. Voronez et in Gubern. Tschernigow Tschern. (herb. Univ. Chark. in Lithuania Wolfg. circa Twer Tschern. (herb. Univ. Chark.) in Sibiria Adams (herb. MB.) ... In Caucaso etc Tauria MB. (A. italica prias, ad Tanain MB, Stev. in Desertis Baschkirorum Eversman (herb Stev.) ad Borysthenem Stev. (herb. MB.) in Hungaria (A.campestris Roch. herb.) in Volhynia Andrz. in Krasnojarsk Helm (herb. Fisch.) circa Tobolsk (Herb. MB.) ... Circa Paviam Stev. Budae, in Com. Marmoros et in territorio Rakos Hungariae superioris (A. campestris Lang, herb. et. A. lednicensis Rochel herb. et. Spreng. Syst Veg.) Austria (d. Schiverek, MB.) Thuringia (A. campestris brevifolia Wallroth in herb. MB. in Galicia MB. in Volhynia Hortul. Witrell et Andrz. in Curonia Mag. Lindemann».

Artemisia camphorata Vill. var. villarsiana Besser nom. nud. in sched. LECB.

Specimen authenticum: Зап. Европа, Франция, «Artemisia camphorata Vill. a. Villarsiana mihi. Galloprovincia, s.d., [fl.], Herb. Besser», "Artemisia camphorata Villarsiana Besser. Galloprovincia, s.d., Besser Herb. Lindemann» (LECB: 3746!).

Прим. Нам не удалось найти, где данное название было обнародовано, возможно, что это только nominum nudum.

Artemisia canescens Willd. var. fischeriana Besser, 1834, Nouv. Mém. Soc. Imp. Naturalistes Moscou, 3: 45.

Syntypus: Вост. Европа, Россия, Саратовская обл., "Artemisia canescens W. $\gamma$. Fischeriana Bess. A.potentillifolia Fisch. Saratoff, s.d., [fl.], [Tauscher?]. Ex Herbarium H. G. Bongardii» (LECB: 3747!).

По протологу: « $\gamma$. Fischeriana (Bess. Monogr. inédit. c. icone) Folia supra nuda, bipinnatifida, laciniis quandoque serrulatis. Flosculi nudi. A.potentilloefolia Fisch. (Spreng. Syst. Veg. III p. 494 n. 95) Ad Volgam superiorem non ad Borysthenem uti vult Spreng. 1. c.) circa Saratof Londes, Tauscher (herb. Acad. Imp. Sc. Petr, et Med.-Chir. Mosq. Fisch. Stev. MB.); ad limites occidentales Sibiriæ (herb. Prescott); in Sibiria orientali Redowski (herb. Stev.) Steller (herb. Acad. Imp. Sc.)».

Artemisia chamissoniana Besser var. kamtschatica Besser, 1834, Nouv. Mém. Soc. Imp. Naturalistes Moscou, 3: 79, tab. IV. 
Iconotypus (syntypus): Дальний Восток, Камчатка, «Tab. IV.Artemisia Chamissoniana Bess. var. $\xi$. Kamtschatica» (LECB: 3748!).

По протологу: «६. Kamtschatica (Bess Monogr. inédit, c. icon.) ... A. Kitlitzio lecta».

Artemisia chamissoniana Besser var. ochotensis Besser, 1834, Nouv. Mém. Soc. Imp. Naturalistes Moscou, 3: 79, tab. IV.

Iconotypus (syntypus): Дальний Восток, Хабаровский кр., «Tab. IV.Artemisia Chamissoniana Bess. var. ๆ. Ochotensis» (LECB: 3749!).

По протологу: «ฑ. Ochotensis (Bes. Monogr. inédit, c.icon.) ... Circa Ochotsk Kruhse (herb. Fisch.)».

Artemisia chamissoniana Besser var. saxatilis Besser ex Hook. 1834, Fl. Bor.-Amer. 1: 324 .

Syntypus: Сев. Америка, США, Аляска, «Artemisia chamissoniana Bess. $\beta$. saxatlis Besser. Unalaschka, s.d., sine coll. Herb. Lindemann», «Artemisia Chamissiniana Bess. var. $\beta$. Unalaschka», "Artemisia arctica Less. $\beta$. unalschcensis Bess. 1831, Unalaschka, s.d., [fl.] Eschscholtz. Ledeb. flor. ross. 515-64» (LECB: 3823!).

По протологу: «ß. saxatilis (Bess Monogr. ined.) squamæ sunt ovatæ margine sphàcelatæ. In Rocky Mountains, et in Unalaschcensi specimine (herb. Lindem.)».

Artemisia chamissoniana Besser var. unalaschcensis Besser, 1834, Nouv. Mém. Soc. Imp. Naturalistes Moscou, 3: 78, tab. IV.

Iconotypus (syntypus): Сев. Америка, США, Аляска, «Tab. IV.Artemisia Chamissoniana Bess. var. $\gamma$. unalaschcensis» (LECB: 3750 !).

По протологу: « $\gamma$. unalaschcensis (Bess. Monogr. . ined. c. icon.) ... in Kamtschaticis Chorisianis et Unalaschcensibus Langdorfianis speciminibus».

Artemisia cina O. Berg, 1862 - Dec 1863, Darstell. Beschr. Off. Gew. 4 (29): tab. 29c. Syntypus?: Ср. Азия, Казахстан, "Artemisia cina Berg Flora turkestanica. Tschimkent, s.d., [fl.], [sine coll.]. Ex herbario horti Petropolitani» (LECB).

По протологу: ?

Прим. Нам не удалось ознакомиться с протологом этого вида.

Artemisia coerulescens L. var. sprengeliana Besser, 1834, Bull. Soc. Imp. Naturalistes Moscou, 7: 26.

Syntypus?: Центр. Европа, Германия, «Artemisia coerulescens L. Osero, auf sumpfigen Stellen am Meeresufer. Aug. Noe n. 969 [Reichenbach. Flora germanica exsiccata n. 969]» (LECB: 3754!).

По протологу: образцы и распространение новой разновидности Бессером в протологе не указаны.

Artemisia commutata Besser, 1835, Bull. Soc. Imp. Naturalistes Moscou, 8: 70.

Syntypus: Сибирь, «Artemisia commutata Bess. Sibiria. s.d., [fl.], Haupt. Ex Herbar. horti Petropolitani», «Artemisia commutata Bess. Sibiria, Haupt. Herb. Ed. a Lindemann» (LECB: 3751!). 
Прим. Смешанный материал на одном гербарном листе с A. arenaria DC. (LECB: $3752 !)$.

Syntypus?: Вост. Европа, Башкирия?, «Artemisia commutata Bess. Ross. austr. s.d., [fl.], sine coll. Herbar. Th. Bienert. Ex Herbarium H. G. Bongardii» (LECB!).

По протологу: "29. Commutata (Bess. Monogr. ined. c. icon. A. desertorum Bess. in Hook. Flor. Borealia-Americana I.p. 325. A. campestris alpina Ledeb. Fl. Alt. IV 3 p. 86) ... A Persia caspica, Baschkiria a regione altaica et Jenisea prope Krasnojarsk incipiendo, partem meridionalem Gubernii Ircutensis et Kamtschatkam occupat et per Americain septentrionalem late sese extendit. (v. sp. s. et c. v. et s.)».

Artemisia deserti Krasch. 1936, Список раст. Герб. фл. СССР, 10: 106, экс. № 3199а, № 3199b.

Syntypi (2): Ср. Азия, Туркмения, «Artemisia deserti H. Krasch. n. sp. ... Туркменская ССР. Горы Кюрен-даг, на высохших галечных руслах истоков близ ж.д. ст. Казанджик. - Turcomania. montes Kopet-dagh pr. stationem viae ferreae Kazandzhik, in glareosis siccis rivuloribus, 20 X 1915, [fl., fr.], Н. Андросов / N. Androssov. Herbarium Florae URSS n. 3199a» (A, GH, H, K, LE, LECB: 2225-2226!, M, S, WIS).

Syntypus: Ср. Азия, Туркмения, «Artemisia deserti H. Krasch. Cf. supra № 3199a ... Туркменская ССР. Ст. Казанджик, предгорья Кюрен-даг, по сухим руслам и каменистым склонам. - Turcomania. In promontoriis Kjuren-dagh pr. stationem Kazandzhik. 8 VII 1930, [fl.], Е. Бобров / E. Bobrov. Herbarium Florae URSS n. 3199b» (K!, LE!, LECB: $2224 !)$.

По протологу: «3199a. Artemisia deserti H. Krasch. sp. n. ... Туркменская ССР. Горы Кюрен-даг, на высохших галечных руслах истоков близ ж.д. ст. Казанджик. Собр. Н. Андросов. - Turcomania. montes Kjuren-dagh pr. stationem viae ferreae Kazandzhik, in glareosis siccis rivuloribus. Leg. N. Androssov. 1915 X 20 ... 3188b. Artemisia deserti H. Krasch. Cf. supra № 3199a ... Туркменская ССР. Ст. Казанджик, предгорья Кюрен-даг, по сухим руслам и каменистым склонам. Собр. Е. Бобров. Turcomania. In promontoriis Kjuren-dagh pr. stationem Kazandzhik. Leg. E. Bobrov. 1930 VII 8».

Artemisia desertorum Spreng. 1826, Syst. Veg. 3: 490

Syntypi? (2): Вост. Европа, культ., «Artemisia desertorum Spr. (1826). Hort. Dorp. 1818. Herb. Lindemann 2730.39» (LECB: 3755-3756!).

По протологу: «Tataria (A.chrysanthemifolia hort. Paris.)».

Artemisia desertorum Spreng. var. sprengeliana Besser, 1835, Bull. Soc. Imp. Naturalistes Moscou, 8: 65.

Syntypi (2): Вост. Европа, культ., «Artemisia desertorum L. a. Sprengeliana Bess. (1835). Hort. Dorp. Herb. Lindemann» (LECB: 3757-3758!).

По протологу: «а. Sprengeliana (Bess. Monogr. ined. c. icon.) ... A. desertorum Spreng, ex autopsia speciminum ab ipso auctore (herb. Rochel.). Circa Tobolsk Haupt (herb. МБ.) in collibus siccis Ircutlae Idem (A. striata herb. Fisch.) et ad torrentem Kudan Tuftsch. In hortis botanicis occurrit sub nominibus A.desertorum, neglectae et pauciflorae». 
Artemisia desertorum Spreng. var. willdenoviana Besser, 1835, Bull. Soc. Imp. Naturalistes Moscou, 8: 67.

Syntypus: Вост. Европа, культ. «Artemisia desertorum L. a. Willdenowiana Besser (1835). Cult. 1833, [fl.], Herb. Lindemann» (LECB: 3759!).

Syntypus?: Вост. Европа, «Artemisia maritima var. $\gamma$. Willd. in deserto, s.d., [fl.], sine coll. Ex Herbarium H. G. Bongardii» (LECB!).

По протологу: « $\delta$. Willdenoviana (Bess. Monogr. ined. c icon.). ... A. neglecta Spr. in Willd. En. 10 A.pauciflora Spreng. Syst. veget. III p. 491 n. 50 exclus, synonymis et patria, excepta Sibiria».

Artemisia dracunculus L. var. pratorum Krasch. 1936, Список раст. Герб. фл. СССР 10: 92, экс. № 3179.

Isotypus: Ср. Азия, Казахстан, «Artemisia dracunculus L. var. pratorum H. Krasch. hoc loco ... Казахская АССР. Пойма р. Иргиз близ г. Иргиза. - Kazahstania. In valle fl. Irgiz prope opp. Irgiz, 20 VII 1909, [fl., fr.], О. Кнорринг / O. Knorring. Herbarium Florae URSS n. 3179» (GH, LECB: 2227!, M).

Holotypus: LE.

По протологу: «3179. Artemisia dracunculus L. var. pratorum H. Krasch. hoc loco ... Казахская АССР. Пойма р. Иргиз близ г. Иргиза. Собр. О. Кнорринг. - Kazahstania. In valle fl. Irgiz prope opp. Irgiz Leg. O. Knorring. 1909 VII 20».

Artemisia eschscholtziana Besser, 1834, Nouv. Mém. Soc. Imp. Naturalistes Moscou, 3: 24 .

Isotypus: Океания, США, Гавайские о-ва, «Artemisia Eschscholtziana mihi $\mathrm{E}$ Wahu, s.d., [fr.], Mertens» «Artemisia Eschscholtziana Besser. E montibus Wahu, Insula Sandwich. XI 1816, [fr.], Eschscholz. Besser [det.]. Herb. Lindemann» (K, LECB: 3760!).

Прим. Это также возможный синтип для Artemisia australis Less. 1831, Linnaea 6: 522 .

По протологу: «Eschscholtziana (Bess. Monogr. inedit. c. icon.) ... In Wahu insularum Sandwichensium cacuminibus montium Eschsch. (v. sp. s.)».

Artemisia eriocarpa Bunge, 1851, Mém. Acad. Imp. Sci. St.-Pétersbourg divers Savans, 7: 336 (Lehm. Reliq. Bot.: 160); Bunge, 1852, Beitr. Fl. Russl. 160.

Syntypus: Ср. Азия, Казахстан, «A. eriocarpa Batkak-Kum, in Flugsande, 21 IV 1842, [fl.], [leg. Lehmann]. Ex Herbarium H. G. Bongardii» (LECB!).

По протологу: «Наb. Häufig in der Wüste Kisil-kum 22. Juli 1841 (fructifera, foliis plerisque emarcidis, capitulis paucis superslitibus); grosse sirauchartige Rasen im Sande zwischen Agatme und Karagata 16. April, im Flugsande Batkak-kum 21. April im Jaman Kisil-kum 22. April 1842 (florens)».

Artemisia fasciculata Bieb. 1808, Fl. Taur.-Cauc. 2: 293. = A. incana (L.) Druce.

Syntypus: Центр. Кавказ, Грузия, «Artem. tiflinensis Adami, Iberia, s.d., [fl.], m. Bieberstein. Herb. Lindemann», «Artemisia fasciculata MB. a. iberica Bess. 1834. Ledeb. flor. ross. 515-48» (HAL, LECB: 3761!).

Syntypus: Центр. Кавказ, Грузия, «Artemisia fasciculata MB.Cauc. s.d., [fr.], Ex herb. Bieberst. Ex Herbarium H. G. Bongardii» (LECB: 3762!). 
По протологу: «Absinthium orieniale incanum tenuifolium, floribus luteis in capitulum congestis et furfum spectantibus. Tournef. cor. p. 34. (ex autopsia herbarii Tournefortiani!) Tanacetum perenne incanum, Absinthii austriaci folio. Vaill. act. paris. a 1719. p. 281. Frequens in rupestribus Iberiae, ad Cyrum fluvium, prope Tiflin. Floret Auguflo, Septembri».

Artemisia fasciculata Bieb. var. armeniaca Besser ex DC. 1838, Prodr. 6: 116.

Syntypus: Юж. Закавказье, Армения, «Artemisia fasciculata $\beta$. Erivan ad sabisfodinas Kulp. Szovits 33. Ex herbario horti Petropolitano» (LECB: 3763!).

По протологу: « $\beta$. Armeniaca (Bess.! l. c), fol. lobis acotiasculis longioribns, capitulis racemoso-corymbosis paniculatis oblongis, invol. squamis laxiusculis pubescentibus, achamiis obovatis obliquis depressis. - in Armeniae lapidosis ad fluv. Zanga prov. Erivan (Szow.!). A. fasciculata tenuiloba Fisch. et Mey!! in litt. Tanacetum orientale Willd. sp. 1812. ex syn. et descr. sed specim. herb. Willd. dicuntur dubia. (v. s.)».

Artemisia fasciculata Bieb. var. iberica Besser ex DC. 1838, Prodr. 6: 116.

Syntypus: Центр. Кавказ, Грузия, «Artem. tiflinensis Adami, Iberia, s.d., [fl.], m. Bieberstein. Herb. Lindemann», «Artemisia fasciculata MB. a. iberica Bess. 1834. Ledeb. flor. ross. 515-48» (LECB: 3761!).

Syntypus: Центр. Кавказ, Грузия, «Artemisia tifliensis Adams», «Artemisia fasciculata MB. a. iberica Caucasus, Ledebour. Herb. Lindemann», «Grusia» (LECB: 3765!).

Syntypus: Юж. Закавказье, Армения, «Artemisia fasciculata a. Ad fluv. Zanga prov. Erivan, s.d., [fl.], Szovits n. 33a. Ex herbario horti Petropolitano. Ex Herbarium H. G. Bongardii» (LECB: 3764!).

По протологу: «а. Iberica. (Bess. 1. c.), fol. lobis breviorihns obtusis, capitulis corymboso-fasciculatis subsessilibus subpaniculatis ovatis, invol. squamis subsericeo- canescentibus adpressis, achaeniis cuneato-lanceolatis obtusis rectis ancipitibus. - in Iberia (Stev.!), Caucaso, in montibus salsis prov. Erivan (Szow.!). Tanacetum incanum Linn. spec. 1183? Desf. cor. Tourn. p. 47. t. 36. ann. mus. h. n. Par. xi. p. 163. t. 21. (v. s.)».

Artemisia glabella Kar. et Kir. 1841, Bull. Soc. Nat. Mosc., 14, 3: 441 (№ 460).

Isolectotypus: Ср. Азия, Казахстан, «Artemisia glabella Kar. (1841). Sibiria alt., inter Buchtarminsk et Krasnye-Jarki, s.d., [fl.], Karelin (n. 803). Ledeb. Flor. Ross. 515-30», «Artemisia glabella Kar. Ledeb. sp. 30. Herb. Ed. Lindemann» (H, K, LECB!, M, NY, P!).

Lectotypus [16]: «a. 1840, № 803» - MW.

По протологу: «In rupestribus inter Buchtarminsk et Krasnye-Jarki».

Прим. П.П.Поляков [17] отождествлял этот таксон с A. obtusifolia Ledeb. 1833, но Н. С. Филатова [18] доказала самостоятельность этого вида.

Artemisia globularia Cham. ex Besser, 1834, Nouv. Mém. Soc. Imp. Naturalistes Moscou, 3: 64. 1834.

Syntypus: Сев.-Вост. Азия, Россия, Чукотка, «Artemisia globularia Cham. Sin. St. Laurent. s.d., [fl.], Eschscholtz. Herb. Lindemann», «Artemisia globularia Cham. ex Bess. (1834). Besser de Abrotan. 1832, pag. 68. Ledeb. flor. ross. 515-52» (LECB: 3766!).

Syntypus: Сев.-Вост. Азия, Чукотка, «Artemisia globularia Cham. Sin. St. Laurent. s.d., [fl.], Eschscholtz. Ex Herbarium H. G. Bongardii» (LECB: 3767!). 
По протологу: «46. Globularia (Chamiss. herb. Bess. Monogr. inédit, c. icon.) cæspitosa, calathidibus racemoso-capitatis, globosis in caule simplici, superne lanato, subaphyllo; flosculis nudis; foliis subtus sericeis tripartitis, laciniis trifidis, integrisve; - ad sinum S. Laurentii ab ipsissimo Prof. Eschscholtz et in herb. Stev. (ab ipso cl. Chamissone) Fisch. Lindem. Acad. Imp. Sc.) (v. sp. s.)».

Artemisia glomerata Ledeb. 1815, Mém. Acad. Imp. Sci. St. Pétersbourg Hist. Acad. 5: 564 .

Syntypus: Сев.-Вост. Азия, Россия, Чукотка, «Artemisia glomerata Ledeb. Sin. St. Laurent. 1793, [fl.], Merk. Ledeb. flor. ross. 515-50», «Artemisia arctica Rudolphi Ad Sinum St. Laurentii (prope fretum Beringii) a b. Merckio lecta 1793 ...», «Artemisia arctica Rud. non Less. Herb. Lindemann» (LECB: 3768!).

Topotypus: Сев.-Вост. Азия, Чукотка, «Artemisia glomerata Ledeb. Sin. St. Laurent. 20 VII 1817, [fl.], Eschscholtz. Herb. Lindemann» (LECB: 3769!).

Прим. Образец смонтирован на одном листе с синтипом.

По протологу: «Нab. ad sinum St. Laurentii».

Artemisia halodendron Turcz. ex Bess. 1835, Bull. Soc. Nat. Mosc. 8: 19; Turcz. ex DC. 1838, Prod. 6: 94.

Syntypus?: Вост. Сибирь, Россия, Бурятия, «Artem. Halodendron. Dahuria, s.d., [fl.], sine coll. Ex Herbarium H. G. Bongardii» (LECB: 3771!).

Syntypus: Вост. Сибирь, Россия, Бурятия, «Artemisia halodendron Turcz. Dauria, Argun. s.d., Maxcz. [?] [Turczaninow?]» (LECB: 3770!).

По протологу: «3. Halodendron (Turtschan. in Litt. Bess. Monogr. inedit. cum icone) ... In salsis ad fluvium Chailar in Dahuria Chinensi et ad fluvium Argun Dahuriae rossicae. Idem. (v. sp. s.)».

Artemisia herbacea Ehrh. ex Willd. 1803, Sp. Pl., ed. Willd. 3, 3: 1828. = A. abrotanum L.

Syntypus?: Зап. Сибирь, «Artemisia herbacea Ehrh. in W. (1803) Sibiria ural., s.d., [fl.], sine coll. [J.Gmelin?] Ledeb flor. ross. 515-34», «Artemisia herbacea Ehrh. Siberia. Herb. Lindemann 2730.72» (LECB: 3772!).

По протологу: «Artemisia herbacea. Ehrh. Krautartiger Beyfus. W. Habitat in Sibiria. 24. (v. v.)».

Artemisia hololeuca M. Bieb. ex Besser, 1834, Nouv. Mém. Soc. Imp. Naturalistes Moscou, 3: 46.

Syntypus: Вост. Европа, Украина, «Artemisia hololeuca MB. ex Bess. 1834 Charcov, s.d., [fl.], Czernajew. Ledeb. flor. ross. 515-43», «Artemisia hololeuca MB. In cretaciis ad fl. Oskol Distr. Kupensk Gub. Charkov. s.d. Herb. Besser» (LECB: 3773!).

Syntypus: Вост. Европа, Россия, Воронежская обл., «Gouv. Woronesch», «Artemisia hololeuca MB. Schrank 1822 legit Czernajew Herb. Lindemann» (LECB: 3774!).

Syntypus: Вост. Европа, Украина, «Artemisia hololeuca Gub. Tschernigoff, circul. Ostrogorsk 1828, sine coll. [Czernajew?]. Ex Herbarium H. G. Bongardii» (LECB: 3775!).

По протологу: «28. hololeuca (MB. in lit. Bess. Monogr. inédit, c. icon.) suffruticosa, cæspitosa; caulibus adscendentibus; calathidibus paniculatis, globosis, subnutantibus; 
panicula aphylla, patula; pericliuiis foliisque tomentosis, niveis; inferioribus bi-, superioribus simpliciter pinnatisectis, laciniis linearibus obtusis. Colles cretacei ad fluvium Oskol et Donnez in Gub. Woronez et Distr. Kupensk Cub. Chark. Czerniejef (herb. MB. et Univ. Imp. Chark.) (v. sp. s. et c. v. et s.)».

Artemisia incana B. Keller var. erecta B. Keller, 1936, Fl. Jugo-Vost. Evr. Chasti SSSR, 6: 354 , descr. ross.

Syntypus?: Ср. Азия, Казахстан, "Artemisia maritima L.ssp. fragrans (Willd.) Ldb. var. Lercheana (Willd.) Ldb. Окр. г. Уральска, 1 IX 1910, [fl.], В. Бородин. Herbarium Horti Botanici Imperialis Petri Magni.», «Большой систематическій Гербарій Туркестана n. 4445. Ex Herbario Horti Petri. Magni», "Artemisia incana Kell. var. erecta Kell.», «Флора Юго-Востока Европейской части CCCP: вып. VI, стр. 355-356. Determ. Г. Мельвиль» (LECB: 3776!).

По протологу: распространение не указано и образцы не процитированы.

Artemisia involucrata Turcz. ex Ledeb. 1851, Fl. Ross. 2, 2: 598, in syn. sub A.frigida Willd.

Specimen authenticum: Вост. Сибирь, Забайкалье, «Artemisia involucrata Turtsch.! Sibiria Transbaical, s.d., [fl.], Turtschaninow. Ex Herbarium H. G. Bongardii» (LECB: 152!).

По протологу: «A. involucrata. Turcz. pl. exs. 1829».

Artemisia juncea Kar. \& Kir. 1842, Bull. Soc. Imp. Naturalistes Moscou 15: 383.

Syntypus: Ср. Азия, Казахстан, «Artemisia juncea Kar. \& Kir. Ajagus Fluseufr. s.d., [fr.], Schrenk. Herbar. Th. Bienert. Ex Herbarium H. G. Bongardii» (LECB!, W!).

По протологу: «447. Artemisia juncea Kar. et Kir. ... Hab. in salsis Songoriœ ad fl. Ajagus rarior. Fl. Augusto. pl. - Specimen non florens hujus plantes vidimus in herbario Lessingiano».

Artemisia kelleri Krasch. 1930, Otchety Rabot. Pochv.-Bot. Otriada Kazakhsk. Eksped. AN SSSR, 4, 2: 247.

Syntypus?: Ср. Азия, Туркмения, «Artemisia Kelleri H.Krasch. ... Туркменская ССР.Пески близ ж.д. ст. Ахча-куйма. - Turcomania. In arenis prope stationem viae ferrae Achca-kuima, 29 IX 1913, [fl.], К. Андрющенко / K. Andrjusczenko. Herbarium Florae URSS n. 3188» (LECB: 3777!).

По протологу: ?

Прим. Нам не удалось ознакомиться с протологом для этого вида.

Artemisia kemrudica Krasch. 1930, Otchety Rabot. Pochv.-Bot. Otriada Kazakhsk. Eksped. AN SSSR, 4, 2: 270.

Syntypus: Ср. Азия, Казахстан, «Artemisia kemrudica H. Krasch. (A.herba-alba Asso ssp. kemrudica H. Krasch.) determ. H. Krascheninnikov» (LECB: 3778!).

По протологу: ?

Прим. Нам не удалось ознакомиться с протологом для этого вида. 
Artemisia knorringiana Krasch. 1914, Bull. Jard. Bot. Petersb. xiv. 463.

Syntypus: Ср. Азия, Узбекистан, «Art. Knorringiana H.Krasch. (n. sp.) (опр. Н. Крашенинников) Ферг. обл. Ошскій у. У переправы черезъ Кызыл-су бугристые пески, 1 VII 1913, [fl.], O.von Knorring. Iter ad distr. Osch 1913. Экспедиція Переселенческаго Управления О.Э.Фонъ-Кноррингъ. Экспедиція въ Ошскій уъздъ 1913 г.», «Ex Herbario Horti botanici Imperialis Petri magni. Большой систематическій Гербарій Туркестана n. 4444.» (LECB: 3779!).

По протологу: «Географически ареалъ: Ферганская область; Ошский уъздъ. Долина Алая, галечникъ, 30, VIII, 1911 г. № 83; холмы въ Алайской долинъ близъ Бордабы, 31, VIII, 1911 г. № 115 (Б.А.Федченко и Р. Ю. Рожевицъ)! У переправы черезъ Кизилъ-су; бугристые пески, 1, VII, 1913 г, № 709 (О.Э. фонъ Кноррингъ)! Маргеланскій у.; Алайская долина; уроч. Команъ; щебенчатые холмы, 29, VI, 1913 г. № 1470 (Н.А.Десятова)!».

Artemisia korotkyi Krasch. 1936, Schedae Pl. Herb. Fl. URSS 10: 73.

Syntypus: Вост. Сибирь, Россия, Бурятия, «Artemisia Korotkyi H. Krasch. sp. n. ... Впервые A. Korotkyi H. Krasch. была собрана в Даурии в прошлом столетии Власовым ... новые весьма обширные (более 50 листов) сборы Короткого и Лебедевой тоже из Забайкалья дают достаточный материал для того, чтобы выделить данную форму во вполне самостоятельный вид ... Бурято-Монг. АССР. Район Еравинских озер, между Б. и М. Еравинскими озерами, на солнце. ... Sibiria orientalis. Transbaicalia. Inter lac. Bolschoi et Malyi Eravinskoe, in locus salsis. 6 VIII 1912, [fl.], М. Короткий, 3. Лебедева, М. Окушко / M. Korotky, Z.Lebedeva, M. Okuschko. Herbarium Florae USSR n. 3151» (H, K, LECB: 3780!, M!).

По протологу: «3151. Artemisia Korotkyi H. Krasch. sp. n. ... Впервые A. Korotkyi H. Krasch. была собрана в Даурии в прошлом столетии Власовым ... новые весьма обширные (более 50 листов) сборы Короткого и Лебедевой тоже из Забайкалья дают достаточный материал для того, чтобы выделить данную форму во вполне самостоятельный вид ... Бурято-Монг. АССР. Район Еравинских озер, между Б. и М. Еравинскими озерами, на солнце. Собр. М. Короткий, 3. Лебедева, М. Окушко. - Sibiria orientalis. Transbaicalia. Inter lac. Bolschoi et Malyi Eravinskoe, in locus salsis. Leg. M. Korotky, Z. Lebedeva, M. Okuschko. 1912 VIII 6».

Artemisia krascheninnikoviana Besser var. macrophylla Besser, 1834, Nouv. Mém. Soc. Imp. Naturalistes Moscou, 3: 41.

Syntypus: Вост. Сибирь, Россия, Бурятия, «Artemisia Krascheninnikowiana Bess. a. macrophylla Fisch. Dahuria, inter Schimi et Turan, s.d., [fl.], Turcz[aninow]. Ex Herbarium H. G. Bongardii» (LECB: 3781!)

Прим. = A. laciniata Willd. IV 2015 А. Коробков.

По протологу: «а. Macrophylla (Fisch. herb. Bess. monogr. inédit c. icon.). ... Dorominsk in Ircutia (herb. Acad. Imp. Sc.) ... Krascheninnikovio in eodem herbario ... Dorominsk (herb. Acad. Imp. Sc. et Fisch.) culla in herb. Fisch. MB. et Stev. - d.) foliorum laciniis angustioribus ad thermas Turkenses Turtschaninov». 
Artemisia leontopodioides Fisch. ex Besser, 1834, Nouv. Mem. Soc. Nat. Mosc. 3: 63.

Syntypus: Дальн. Восток, Россия, Курильские о-ва, «Artemisia curilensis = leontopodioides Fisch. Kurilen, s.d., [fl.], sine coll. Ex Herbarium H. G. Bongardii» (LECB: 3782!).

По протологу: «(Fisch. herb. Bess. Monogr. inedit. c. icon.) ... In insulis Curilensibus et Kamtschatka herb. Fisch. (v. sp. s.)».

Artemisia leucodes Schrenk, 1844, Bull. Phys.-Math. Acad. Petersb. 3: 106.

Syntypus: Ср. Азия, Казахстан, «Artemisia leucodes Schrenk. s.d., Schrenk Iter Soongaricum», «Большой систематическій Гербарій Туркестана n. 4443. Ex Herbario Horti Petri. Magni» (LECB: 3783!).

Syntypus: Ср. Азия, Казахстан, «Artemisia leucodes Schr. In sandigen Boden an der Ile. 13 VIII 1843, [fl.], Schrenk n. 166. Ex Herbarium H. G. Bongardii» (LECB: 3784!).

По протологу: «In locis arenosis, versus fluvium Ile» [leg. Al. Schrenk].

Artemisia maritima Besser var. blumiana Besser, 1834, Bull. Soc. Imp. Naturalistes Moscou, 7: 32.

Syntypus: Вост. Европа, «Artemisia maritima L. $\delta$. Blumiana mihi Vertat [?]» (LECB: $3786 !)$.

Syntypus: Вост. Европа, культ. в Прибалтике, «Artemisia nitens Hort. Dorp. s.d., Herb. Lindemann», «Artemisia maritima . Blumiana Besser Hort. Dorp. 1816, [fl.], Herb. Lindemann» (LECB: 3785 !).

Syntypi (2): Вост. Европа, Россия, Астраханская обл., "Artemisia nutans W. 1800 Astrachan, s.d., [fl.], herb. Lindemann», «Astrachan», "Artemisia nutans W. (1803). Artemisia maritima Bess. (1834) $\gamma$. nutans Ledeb. b. incana / $\delta$. Blumiana Bess. 1834» (LECB: 3787, 3789!).

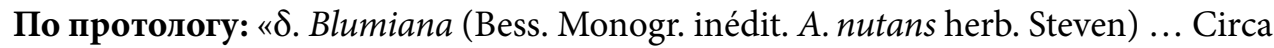
Berislav Molotschna in rupibus ad Ingul et Ingulez Gub. Cherson (herb. Steven.) E monte Bogdo ad Volgam (herb. Prescott.) In desertis ad Caucasum (herb. Fisch.) ad mare Caspicum Hermann (Herb. Acad, Imp. Med.-Chir. Mosqu et Prescott.) - Huc quoque A. nitida e Horto Dorpat. (Herb. Lindem.)».

Artemisia maritima Besser var. boschniakiana Besser, 1834, Bull. Soc. Imp. Naturalistes Moscou, 7: 39.

Syntypus: Вост. Европа, Крым, «Artemisia maritima L. $\mu$. Boschniakiana mihi Taur. Fleisch. herb.», «Artemisia maritima $\mu$. Boschniakiana Besss. Besser de Serfidiis 1833 pag. 39» (LECB: 3790!).

Прим. Синтип смонтирован на одном гербарном листе вместе с нетиповым образцом из Крыма, собранным Э. Линдеманном в 1884 г.

По протологу: « $\mu$. Boschniakiana (Bess. Monogr. inédit. c. icon. A. nutans. Tschern.) panicula terminalis oblonga, ramis dense spicatis foliisque tripinnati-sectis incanis. Circa Odessam Szowitz. Ad Borysthenem in saxosis distrietus Orechov Gub. Cherson (Tscherniajef.) E Tauria in herb. D. Fleischer».

Artemisia maritima Besser var. hablitziana Besser, 1834, Bull. Soc. Imp. Naturalistes Moscou, 7: 42.

Syntypus: Вост. Европа, Крым, «Artemisia maritima Bess. (1834) $\pi$. Hablitziana Besser 1834, Tauria, s.d., [fl]. Fleischer. Herb. Lindemann» (LECB: 3791!). 
По протологу: «л. Hablitzlana (Bess. Monogr. inédit, c. icon.) ... - Circa Odessam Szowitz, in Tauria (A.nutans) Steph. MB. herb. D. Fleisch. Kisliar Stev. Mons Bogdo (herb. Acad. Imp. Med.-Chir. Mosq.) Calathidia nutantia; tarnen erecta in Tauria Beaupré (herb. Stev. et Fleisch.)».

Artemisia maritima Besser var. kitaibelliana Besser, 1834, Bull. Soc. Imp. Naturalistes Moscou, 7: 40.

Syntypi (2): Вост. Европа, Россия, Астраханская обл., «Artemisia maritima L.o Kitaibeliana mihi / var. nutans / A. salina Schult. non W., Dr. Fleischer Herb.», «Astrachan», «Artemisia monogyna Kit. 1802 Astrachan, Ledeb. flor. ross. 515-21» (LECB: 3793!).

Syntypus: Вост. Европа, Украина, «Artemisia maritima L. o Kitaibeliana mihi In salsis maritimis Odessa. Herb. W. Besser», «Odessa», «Artemisia maritima L. o Kitaibeliana Bess. (1834), Odessa, Besser. Herb. Lindemann» (LECB: 3792!).

По протологу: «о. Kitaibeliana (Bess. Monogr. inédit. A. monogyna Waldst. et Kitaib. Icon. pl. rar. Hung. I.p. 77. t. 75 A. salina Schult. Oestr. Flora II. p. 484. exclus. Synon.) ... In Hungaria, Bannatu, circa Odessam Szowitz, Andrzejofski, in Tauria (herb. Presc.) Beaupré, Stev. et MB. Nikopoli (herb. Prescott.) Taganroci ad Mare Asov (Tschern.) Circa mare Casp. Gmel. junior (A. larycifolia) In Ucrania circa Slabensk. (Tschern.) circa Orenburg, in montibns Inderiens. Karelin (herb. Imp. Univer. Chark.) ad lacuna. Inderiens. (herb. Acad. Imp. Sc.) ad Tanain et ad Caucasum (herb. Acad. Imp. Med.-Chir. Mosqu.) circa Kisliar, Stev. circa Sareptam et in transvolgensibus Tauscher (herb. MB. et Fisch.) e monte Bogdo (herb. Prescott.) in Gub. Tambov et Woronesch MB. ad Salinas Ilezk (herb. Fisch.), ad flumen Wagram in Petropawlovski Zawod Dr. Wagner (herb. Wolfgang); ad salinas Krasnojarenses (herb. Acad. Imp. Sc.) ad flumen Aldanum Ircutiae (herb. Stev.) ex aliis locis Sibiriae Steller. (herb. Acad. Imp. sc.) Salesov (herb. MB.). Variat canescentia majori et minori - fere Candida est A. larycifolia Gmel. jun. - panicula depauperata oblonga et amplissima, patula, patente et divaricata-circa Astrachan (herb. Acad. Imp. Med.-Chir. Mosqu.) - calalhidibus magis fuscis et pallidioribus erectis et nutantibus que in Pannonia quam in Imperio rutheno. Cultae in horto Luxemburgensi Parisiis a Gaio...».

Artemisia maritima Besser var. lercheana (Stechm.) Besser f. europaea Besser, 1834, Bull. Soc. Imp. Naturalistes Moscou, 7: 37.

Syntypus: Центр. Европа, «Artemisia maritima Ledeb. ఢ. Lercheana Ledeb. 1846. a.

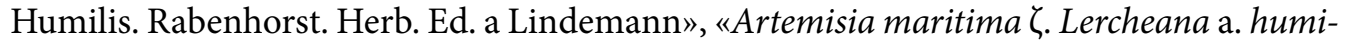
lis Ledeb. Meerstrandsbeifuss, Lerche'sche Abart, niedere Form. Ververdung, Vaterland u.s.w. bei No. 362» (LECB: 3795!).

По протологу: «а. Europaea (A. filaginoidea, Stech. A. vallesiaca Ait.) Planta alpina Helvetiae et Vallesiae ... et tali modo non amplius distinguendum est specimen ab ill. Turtschaninovio e Dahuria nomine A. albldo W. missum».

Artemisia maritima Besser var. linnaeana Besser, 1834, Bull. Soc. Imp. Naturalistes Moscou, 7: 37.

Syntypus: Европа, «A.maritima L. a Linneana mihi», «Artemisia maritima L. a Linneana Bess. Herb. Lindemann» (LECB: 3796!).

По протологу: «ع. Linnaeana (Bess. Monogr. inédit. A. maritima Linn. Spec. pl. 1186, n. 7.) panicula patula, pericliniis incanis, foliorum laciniis divergentibus. In litoribus 
Germania? et Galliae borealis, Belgii, Angliae, Suecise, Daniae, Norvegiae. In Dalmatia Portenschlag - (Herb. Imp. Univ. Chark. E Sibiria orientali in herb. Fisch.».

Artemisia maritima Besser var. stechmaniana Besser, 1834, Bull. Soc. Imp. Naturalistes Moscou, 7: 31 .

Syntypus: Вост. Европа, Россия, Астраханская обл., «Artemisia maritima L. $\alpha$. pauciflora Ledeb. Astrachan, s.d., Dr. Blum. Herb. Ed. a Lindemann», «Astrachan», «Artemisia maritima L. a. pauciflora Ledeb. a. Stechmaniana Bess. 1834. Odessa. Ledeb. flor. ross. 515-21» (LECB: 3797!).

Syntypus: Вост. Европа, Россия, Астраханская обл., "Artemisia maritima L.a. pauciflora Ledeb. Astrachan, s.d., [fr.], Dr. Blum. Herb. Ed. a Lindemann» (LECB: 3798!).

Прим. Оба синтипа смонтированы на одном листе вместе с нетиповым образцом из Одессы, собранным самим Э. Линдеманном.

По протологу: «Stechmaniana (Bess. Monogr. ined. A.pauciflora Stechmann. A.p. 26. n. 24. Gmel. Sibir. II.p. 446. n. 4 04. tab. 52. f. 4. 2. A. pulchella Gmel. jun. A. nutans $ß$ MB. in herb. Imp. Univ. Charkow.) panicula fastigiata ? thyrsoidea. - Ad Volgam. Vidi specimina Gmeliniana in herbar. Acad. imp. Sc. et al.)».

Artemisia maritima L. subsp. terrae-albae Krasch. 1921, Not. Syst. Herb. Hort. Petrop. 2: 187.

Syntypus: Ср. Азия, Казахстан, «Artemisia maritima Bess. f. nutans. Семиръченская обл., Джарк. у.: Сары-Чаганъ, 22 VII 1910, [fl.], А. И. Михельсонъ. Гербарій Переселенческаго Управленія. Экспедиція въ Джаркентскій и Пржевальскій у. 1910 г.» (LECB: 3801!).

Syntypi (2): Ср. Азия, Казахстан, «Artemisia terrae albae H. Krasch. ... Казахская АССР. Глинисто-песчаная степь близ ст. Кара-Чокат Оренбург-Ташкентской ж.д. Kazahstania. In steppa argilloso-arenosa artemisiaca prope stationem viae ferrae KaraCzokat inter Czelkar et Kazalinsk. 10 IX 1908, [fl.], Н. Андросов / N. Androssov. Herbarium Florae URSS n. 3192» (LE, LECB: 3799-3800!).

По протологу: «Пустынные степи (белоземы и отчасти буроземы) Киргизского края и С. Туркестана».

Artemisia messerschmidiana Besser var. viridis Besser, 1834, Nouv. Mém. Soc. Imp. Naturalistes Moscou, 3: 28. 1834

Syntypus?: Вост. Европа, культ., «Artemisia sacrorum var. $\beta$. intermedia Ledb. A. Messerschmidtiana a. viridis Bess.», "Artemisia sacrorum Ledeb. $\beta$. intermedia Ledeb. 1833 Cult. 1830 Herb. Lindemann» (LECB!).

По протологу: «а viridis (Bess. Monogr. inédit.) foliis supra nudis, subtus cinereis. A. sacrorum Ledeb. in Mém. de l'Acad. Imp. des Sciences de St. Pétersb. T. V.p. 571. Gmel. Fl. Sib. II p. 422 n. 407 var И. T.LVI.f. 2. A. racemifera Steph. in herb. Prescotti. A. Gmelini herb. Fisch, non Stechm. Hæc est a.) calathidibus majoribus in Dorominsk Dahuriæ (Davuriæ, Daouriæ un um idemque) $\left(^{*}\right)$ Wlassov (herb. Presc. Fisch. MB. Stev. et Acad. Imp. Sc.). In desertis prope Barnaul et in montibus secundariis Altaicis Dr. Gebl. Ad Jeniseum Stell. Adams (herb. Acad. Imp. Sc.) et Ledeb. 1. c. - Racemis brevissimis a Salesovio lecta in herb. MB. - Racemis inferioribus elongatis, longe pedunculatis Dorominsk, Vlassov; 
(herb. Stev.). - b). Calathidia minora in Ircutia Haupt (herb. Acad. Imp. Sc.). Ibidem in collibus siccis legit Turczaninof. Praeterea omnis variat foliis subtus plus minusve incanis».

Artemisia monogyna Walst. \& Kit. var. microcephala DC. 1837-1838, Prodr. 6: 103.

Syntypus: Вост. Европа, Украина, «Artemisia monogyna Kit. (1802) microcephala DC. (1837) Odessa, s.d., sine coll. Herb. Ed. a Lindemann», "Artemisia maritima L. $\gamma$. monogyna a. microcephala DC. Ledeb. flor. ross.» (LECB!).

По протологу: « $\beta$. microcephala ... ad Odessam, in Tauria, circa mare Caspium, Sareptam, Ircutiam, etc. Bess. (v.s.)».

Artemisia nana Gaud. var. racemulosa Reichb. nom. nud.? in sched. LECB!

Syntypus?: Зап. Европа, Франция, «Artemisia nana. Gaud. Rchb. Fl. germ. Novit. 1863. b. Vallée blanche près du Montblanc. Huguenin» n. 826» «Artemisia borealis Pall. Artemisia nana Goud. 1830 3. racemulosa Reichb. Herb. Fleischer» (LECB: 3802!).

\section{По протологу: ?}

Прим. Нам не удалось обнаружить, где данное название было обнародовано.

Artemisia nutans Willd. var. scabriuscula Ledeb. nom. nud.? in sched. LECB!

Specimen authenticum: "Artemisia maritima L. $\gamma$. nutans / a. scabruscula, Tauria, s.d., [fl.], Ledebour. Ledeb. flor. ross. 518-21», «Tauria», «Artemisia maritima L. $\gamma$. wilhelmsiana Bess. Tauria, Ledebour. Herb. Lindemann» (LECB: 3803!).

Прим. Нам не удалось найти, где данное название было обнародовано Ледебуром.

Artemisia pectinata Pall. 1776, Reise Russ. Reich. 3 (2 Anhang): 755, tab. Hh, fig. 2.

Syntypus: Вост. Сибирь, Бурятия, «Artemisia pectinata Pall. (1776), Davuria, s.d. [fl.], Pallas. Ledeb. flor. ross. 515-69», «Artem. pectinata Pall. Herb. Lindemann» (HAL!, LECB: 3804!, LINN).

По протологу: «Plantula elegans, fragrantissima, ad Selengam et Tschikoium, circa vias publicas, praesertim eam, quae Kiachtam ducit, frequens. Floret demum ineunte $\mathrm{Au}$ gusto».

Artemisia piperita Pall. ex Ledeb. VII-XII 1833, Fl. Altaic. 4: 88, in syn. ad A.glauca Pall. $=$ A. scoparia Waldst. \& Kit.

Specimen authenticum: Сибирь, «Artemisia piperita Pall. Sibiria, s.d. Sievers. herb. Lindemann» (LECB: 3811!).

Artemisia procera Willd. var. ledebouriana Besser, 1834, Nouv. Mém. Soc. Imp. Naturalistes Moscou, 3: 30. = A. abrotanum L.

Syntypus: Вост. Европа, Россия, Ростовская обл., «Artemisia praecox W. $\varepsilon$ Ledebouriana Bess. Herb. Lindemann 2730.79», «Artemisia procera affinis Ledeb. Hort. dorpat. 1827, [fl.], Herb. Lindemann» (LECB: 3805!).

Прим. Синтип смонтирован вместе с нетиповым образцом из Франции.

Syntypus?: Вост. Европа, «Artemisia procera 2», «Artemisia procera Herb. Fleischer 2730.79», «Artemisia procera W. ع Ledebouriana Bess. ad Tanain, Henning» (LECB: 3806!). 
По протологу: «ع Ledebouriana (Bess. Monogr. inédit. A. proceræ affinis horti Dorp. 48 27) odoratissima, panicula-magna, foliosa, calathidibus turbinatis parvis, flosculis nudis. Ill. Ledebour ex itinere altaico eam attulisse videtur. In Podolia occidentali spontaneam ac quasi spontaneam legit Andrzejowscius circa Weselce; (A. procera En. pl. Volh. etc. p. 76 n. 4 593.) In hortis rusticis Samogitiæ (Rev. Mag. Fiedorovicz) Gub. Minsk Lithuaniæ, Podoliæ, Volhyniæ et Galiciæ loco A. Abrotani colitur. A.porrigens Fisch, e horto Chelseano herb. Schult. (desideratur in herb. Fisch.). A. tenuissimae Fisch. nomine nuperrime mecum communicavit cel. Sprengel at desideratur æque in ejusdem Syst. Veget. quam in illius herbario. - Culta tamen in horto botanico Chark. (herb. Univ. Imp. Chark.)».

Artemisia procera Willd. var. visianiana Besser, 1834, Nouv. Mém. Soc. Imp. Naturalistes Moscou, 3: 31. - Artemisia naronitana Vis. ex DC. 1838, Prodr. 6: 108, in syn. A procera var. visianiana Bess.

Syntypus: Юго-Вост. Европа, Хорватия, «Artemisia naronitana. Ad fossas in valle Naronae, IX 1829, Hohenwarth», «Artemisia paniculata Lam.! 1783 Herb. Dris botan. Ed. a Lindemann» (LECB: 3807!).

Прим. Синтип смонтирован на одном гербарном листе вместе с нетиповым образцом из Полтавы.

По протологу: «ө. Visianiana (Bess. Monogr. ined. A. naronitana Viv.) E. Dalmatia ab Unione itineraria 1829 communicata».

Artemisia salina (Willd.) B. Keller var. erecta B. Keller, 1936, Fl. Iugo-Vost. Evr. Chasti SSSR, 6: 355, descr. ross.

Syntypus?: Cр. Азия, Казахстан, «Artemisia maritima L. var. incana (DC.) Илекский р-н, песчаные барханы у пос. Кинделинского, на восток, 17 VIII 1928, [fl.], А.Борисова. Оренбургское Почвенно-Ботаническое Бюро. Экспедиция в Оренбургский округ под руководством проф. Б.А. Федченко № 1527», «Artemisia salina (Willd.) Kell. var. erecta Kell.», «Флора Юго-Востока Европейской части СССР: вып. VI, стр. 354-355. Determ. Г. Мельвиль 6 I 1941» (LE, LECB: 3809!).

По протологу: в протологе географическое распространение разновидности не указано и не процитированы образцы.

Artemisia santolina Schrenk, 1844, Bull. Phys.-Math. Acad. Petersb. 3: 106.

Syntypus: Ср. Азия, Казахстан, «Artemisia Santolina Linn Andau Ufaru das Ileé, ... 3 VIII 1843, [fl.], A.Schrenk n. 161», «На берегу ръки Или, песчаномъ мъстъ, 3 VIII 1843, [fl.], [A. Schrenk] n. 498» (LE, LECB!).

По протологу: «Artemisia Santolina Schrenk. ... In ripa fluvii Ile, locis arenosis, initio Augusti m. nondum florentem, inventa».

Artemisia schrenkiana Ledeb. VI 1845, Fl. Ross. 2, 2, 6: 575.

Syntypus: Ср. Азия, Казахстан, «Artemisia Schrenkiana Ldb. sine loco [Tarbagatai], s.d., [fl.], A. Schrenk», «Большой систематическій Гербарій Туркестана n. 4448. Еx Herbario Horti Petri. Magni» (LECB: 3810!).

По протологу: «Hab. in Sibiria altaica ad m. Tarbagatai! (Schrenk). ћ». (LECB!) 
Artemisia scopaeformis Ledeb. VI 1845, Fl. Ross. 2, 2, 6: 575.

Syntypus: Ср. Азия, Казахстан, "Artemisia scopaeformis ? Auf Sandsagola in der naygen [?] der Tschu VIII-IX [1843], [fl.], A. Schenk 120 (171)» (LECB!).

По протологу: «Наb. in Sibiriae altaicae deserto soongoro-kirghisico loco Tschu dicto! (Schrenk pl. exs.). h. 24.

Artemisia senjavinensis Bess. 1836, Bull. Soc. Imp. Naturalistes Moscou, 9: 64.

Syntypus: Дальн. Восток, Россия, Чукотка, «Artemisia senjawinensis Besser, Fret. Senjawin, s.d., [fl.], sine coll. Ex Herbarium H. G. Bongardii», «Senjawin-Strass.» (LECB: $3812 !)$.

По протологу: «р. 65, lin. 11. loco Semavinensis lege Senjavinensis».

Artemisia soongarica Schrenk, 1841, Enum. Pl. Nov.: 49.

Syntypus: Ср. Азия, Казахстан, «Artemisia songorica Schrenk, Balchasch, s.d., [fr.], [Ex] Herb. Th. Bienert. Ex Herbarium H. G. Bongardii» (LECB: 153!).

По протологу: «In montibus Arganaty et versus lacum Balchasch lecta, primis Junii m. diebus florens».

Artemisia stechmanniana Besser var. armeniaca Besser, 1834, Nouv. Mém. Soc. Imp. Naturalistes Moscou, 3: 35, 88.

Syntypus?: Юж. Закавказье, Карабах, «Artemisia filaginoides. - fragrans W. Karabagh, s.d., [fl.], Szovits» (LECB!).

По протологу: «ß armeniaca (Bess. Monogr. inédit.) racemuli rariores magis foliis interstincti; folia tenuiora, rhachi minus alata.; periclinii .squamæ exter, lanceolatæ paucissimæ. In parte meridionali montis Arekligeduk Provinciæ Karabagh. Szovits».

Artemisia steveniana Besser, 1834, Nouv. Mém. Soc. Imp. Naturalistes Moscou, 3: 64. Iconotypus (syntypus): Сибирь, «Tab. III Artemisia Steveniana Bess.» (LECB: 3813!).

По протологу: «45. Steveniana (Bess. Monogr. inédit, c. icon. Tab. III) ... - In terris arcticis Sibiriæ Adams (herb. Stev.) (v. sp. s.)».

Artemisia subspinescens Boiss. Jul 1846, Diagn. Pl. Orient., ser. 1, 6: 91.

Isotypus: Малая Азия, Турция, «Artemisia subspinescens Boiss. Kuh Daena, s.d. [= 3 VIII 1842], Kotschy [n. 782]. Herbar. Th. Bienert. Ex Herbarium H. G. Bongardii» (FI, GH, GOET!, K, LECB: 3815!, M, MO, P, WIS).

По протологу: «Artemisia subspinescens Boiss. loc. cit. Febr. 1845 ... Hab. ad fontem Deschme Pias alpis Kuh-Daëna Kotschy N 782».

Artemisia tenuifolia Willd. 1803, Sp. Pl. 3: 1819.

Syntypus: Азия, «Artemisia tenuifolia W. 1803 Herb. Fleischer XIX.II.2730.71» (LECB!).

По протологу: «10. Artemisia tenuifolia. W. A. frutefcens, caule stricto, foliis bipinnatis capillaceis, floralibus simplicibus calycibus oblongis. W. A. (capillifolia) foliis capillaribus multipartitis viridibus, racemis filiformibus simplicissimis. Lamarck. encycl. 1. p. 264. ${ }^{*}$ Artemisia procerior, foliis et capitulis tenuibus. Dill. elth. 37. t. 35. Dünnblättriger Beysus. W. Habitat iu India orientali, China». 
Artemisia triniana Besser, 1834, Nouv. Mém. Soc. Imp. Naturalistes Moscou, 3: 67, tab. 3 .

Iconotypus (syntypus): Сибирь, «Tab. III Artemisia Triniana Bess.» (LECB: 3814!).

По протологу: «50. Triniana (Bess. Monogr. inédit c. icon. Tab. III.) ... E Sibiria (A. glacialis) herb. Acad. Med.-Chir. Mosq. (v. sp. s.)».

Artemisia umbrosa Turcz. ex DC. 1837, Prod. 6: 113, nom. nud., in syn. cM. Artemisia vulgaris L. var. umbrosa Turcz. ex Bess.

Artemisia vulgaris L. var. kamtschatica Besser, 1834, Nouv. Mém. Soc. Imp. Naturalistes Moscou, 3: 54.

Syntypus: Дальн. Вост., Россия, Камчатка, «Artemisia vulgaris $\xi$. Kamtschatica Bess. Kamtschatka, s.d., [fl.], sine coll.», «Artemisia vulgaris, Kamtschatka, Peter Pauls. Haf... [?]. Ex Herbarium H. G. Bongardii» (LECB: 3817!).

Прим. = A. opulenta Pamp. IV 2015 A. Коробков.

Syntypus: «Artemisia vulgaris $\xi$. Kamtschatica Bess. Unalaschca, s.d., [fl.], Mertens! Ex Herbarium H. G. Bongardii» (LECB: 3818!).

Прим. = A. unalaskensis Rydb. IV 2015, А. Коробков.

По протологу: «६. Kamtschatica (Bess. Monogr. inédit c. icon.) ... E seminibus ab amicissimo Fischero e Kliutschevskaia Kamtschatkae culta Cremeneci. Ex Unalaschka Dr. Mertens. (herb. Acad. Imp. Sc.). E Sibiria orientali (herb. Acad. Imp. Sc. - Med. - Chir. Mosq. et Fischer). In glareosis ad lacum Kossogol Ircut. (A. vulgaris leucophylla Turtschan. herb.)».

Artemisia vulgaris L. var. mongolica Fisch. ex Besser, 1834, Nouv. Mém. Soc. Imp. Naturalistes Moscou, 3: 53.

Syntypus: Вост. Европа (культ.), «Artemisia vulgaris L. $\beta$. tenuifolia Turcz. Ledeb. flor. ross. 515-47», "Artemisia vulgaris L. 1763 ع. mongolica Besser 1834 Cult. 1834 Herb. Lindemann» (LECB: 3819!).

По протологу: «ع. Mongolica (Fisch. Cat. H. Gorenk.) ... In Mongolia, Dahuria (herb. Acad. Imp. Sc. Fisch. Prescott.) - Panicula fere spicata. In cultis et ruderatis Ircutiæ (A. vulgaris tenuifolia Turtschanin. herb.). Huc quoque referenda $A$. indica e Tranquebaria a cel. Sprengelio et ejusdem nominis a D. Schultesio Laudishuti culta benevole mecum communicatae».

Artemisia vulgaris L. var. parviflora Fisch. ex Besser, 1834, Nouv. Mém. Soc. Imp. Naturalistes Moscou, 3: 54. = A. vulgaris L.

Syntypus: Вост. Европа, Украина, «Artemisia vulgaris L. (1762) $\theta$. parviflora Bess. 1834 Charcov. Ledeb. flor. ross.» (LECB: 3820!).

По протологу: « $\theta$. parviflora (Bess. Monogr. inédit.) foliis caulinis bipinnatifidis, laciniis lanceolatis, panicula ampla; calathidibus fere i brevioribus, flosculis purpureis. Volhynia. Vilnae in Lithuania Prof. Wolfgang. A. apelata H. Perth. ex herb. Schuttes. - b) eadem flosculis fulvis in Hungaria (herb. Lang;) - c) eadem foliorum superiorum laciniis lineari-elongatis Charkoviæ Prof. Czerniajef. Orenburgi Karelin (herb. Univ. Imp. Charkov.)». 
Artemisia vulgaris L.var. umbrosa Turcz. ex Bess. 1834, Nouv. Mém. Soc. Naturalistes Moscou, 3: 53. $=$ A. selengensis Bess.

Syntypus: Вост. Сибирь, Россия, Забайкалье, «Artemisia umbrosa Turt.! Sibiria transbaicalensis, s.d., [fl.], Turtschaninow. Ex Herbarium H. G. Bongardii» (LECB: 3816!).

По протологу: «а. umbrosa (Turtschanin. herb. Bess. Monogr. ined. c. icon.) .... a) Talis Selingam in umbrosis Turtschan. - b) Eadem ... sine loco indicato Adams (herb. Acad. imp. Sc.). - c) Eadem ... sine patria indicata Gmel. jun. (in eodem herbario) - d) ... Ad eandem Selengam legit Adams (idem herb.)».

Artemisia vulgaris L. var. vulgatissima Besser, 1834, Nouv. Mém. Soc. Imp. Naturalistes Moscou, 3: 52.

Syntypus: Вост. Европа, культ. «Artemisia vulgaris $\gamma$. vulgatissima Bess», «Artemisia vulgaris Hort. bot. Dorp.» (LECB: 3821!).

По протологу: « $\gamma$. vulgatissima ... Kamtschatka Lubarsky (Fisch. herb.) Apud Baschkiros Heinselmann (herb. Acad. Imp. Sc.) E Kasan et Tyraspol (herb. Presc.) Mitavæ Hag. Lindemann; Amstelodami (herb. Schult.) ... c) Eadem flosculis fulvis in montibus altaicis secundariis Dr. Gebl. ... In Armenia ubique (Szowitz). In desertis sterilissimis (herb. Acad. Imp. Sc.) Hungaria (Rochel. herb.) Volhynia (Andzrejowski). Huc spectat A.vulgaris a. sylvestris, calycibus oblongis pedunculatis in racemos multifloros acutos digestis Wallr. Sched. crit. p. 4 57. - e) Eadem calathidibus brevissime pedicellatis. Landishuti Bojorum (Schultes); Tauria (MB.?) Mitava (Lindem.) - f.) Foliorum laciniis lanceolatis inciso-dentatis, panicula magna, calathidibus brevissime pedieellatis, flosculis purpureis est A. violacea H. Paris. (non Ledeb.) A. rubra Tabernæm. Galicia; Hungaria (spica simplicissima). Vegetior est A. vulgaris v. sativa, calycibus ovato-subglobosis sessilibus in racemos paucifloros obtusos congestis. Wallr. Sched. crit. p. 457».

B настоящее время в LECB выявлены типовые образцы, относящиеся почти ко всем принятым в роде подродам - Artemisia subg. Artemisia, subg. Dracunculus Besser ex Lessing, subg. Seriphidium Besser ex Lessing. В результате в Гербарии LECB выявлено 134 типовых образца для 93 таксонов из родов Absinthium Mill. и Artemisia L. (43 вида, 1 подвид, 48 разновидностей и 1 форма). Это намного больше, чем в других сравнимых коллекциях, хранящихся в университетах России [19-22]. Необходимо подчеркнуть, что публикуемый список, скорее всего, неполный и в будущем может быть дополнен новыми названиями.

Как нам представляется, информация о типовых образцах из рода Artemisia s.l. в Гербарии CПбГУ (LECB) может быть полезна для исследователей семейства Сложноцветные в связи с проектами по изучению флоры Восточной Европы, Кавказа, Юго-Западной и Центральной Азии и Северной Америки, а также монографам этой группы растений.

Литература

1. Бубырева В.А., Бялт В.В., Орлова Л.В. Коллекция Г.П.Бонгарда в гербарии кафедры ботаники Санкт-Петербургского государственного университета (LECB) // Бот. журн. 2003. Т. 88, № 2. C. 125-133.

2. Бубырева В.А., Бялт В.В., Орлова Л.В. Эдуард Эммануилович Линдеманн и его коллекция в гербарии кафедры ботаники Санкт-Петербургского университета (LECB) // Бот. журн. 2003. Т. 88, № 11. C. 156-164. 
3. Бубырева В.А. Коллекции, хранящиеся в Гербарии кафедры ботаники Санкт-Петербургского государственного университета (LECB) // Бот. журн. 2004. Т. 89, № 7. С. 1190-1208.

4. Бялт В. В., Бубырева В.А. Типовые образцы, хранящиеся в Гербарии Санкт-Петербургского государственного университета (LECB). Часть 1. Семейство Ericaceae // Новости сист. высш. раст. 2005. T. 37. C. $208-220$.

5. Бялт В. В., Бубырева В.А. Типовые образцы, хранящиеся в Гербарии Санкт-Петербургского государственного университета (LECB). Часть 2. Семейство Restionaceae // Новости сист. высш. раст. 2005. T. 37. C. 121-227.

6. Бялт В. В., Бубырева В.А. Типовые образцы, хранящиеся в Гербарии Санкт-Петербургского государственного университета (LECB). Часть 3. Семейство Oxalidaceae // Новости сист. высш. раст. 2005. T.37. C. $228-232$.

7. Бубырева В.А., Бялт В.В., Орлова Л.В. Типовые образцы К. Вильденова в Гербарии СанктПетербургского государственного университета (LECB) // Бот. журн. 2006. T. 91, № 1. С. 114-132.

8. Byalt V., Bubyreva V., Orlova L. The history of Eduard Lindemann's collection kept in the Herbarium of Botanical Department of St. Petersburg State University (LECB) // Taxon. 2008. Vol.57, N 1. P. 275-278.

9. Бялт В.В., Бубырева В.А. Типовые образцы, хранящиеся в гербарии Санкт-Петербургского государственного университета (LECB). Часть 4. Семейство Polygalaceae // Вестн. С.-Петерб. ун-та. Сер. 3. Биология. 2012. Вып. 4. С.27-37.

10. Бялт В.В., Бубырева В.А. Типовые образцы, хранящиеся в Гербарии Санкт-Петербургского государственного университета (LECB). Часть 5. Семейство Tamaricaceae // Вестн. С.-Петерб. ун-та. Сер. 3. Биология. 2014. Вып. 3. С. 4-15.

11. Бялт В.В., Бубырева В.А. Хранящиеся в СПБГУ типовые образцы таксонов, описанных В. Л. Комаровым в студенческие годы // Вестн. С.-Петерб. ун-та. Сер. 3. Биология. 2014. Вып. 4. С. 89107.

12. Бялт В. В., Потокин А. Ф., Бубырева В. А. Типовые образцы сем. Апnоnасеае Juss., хранящиеся в гербариях СПБГУ (LECB) и СПбГЛТУ (KFTA) // Вестн. С.-Петерб. ун-та. Сер. 3. Биология. 2014. Вып. 1. С. 55-68.

13. Жизнь растений / под ред. А. Л. Тахтаджяна. М., 1981. Т. 5, ч. 2.512 с.

14. Index Herbariorum: a guide to the location and contents of the world's public herbaria. 8th ed. / Regnum vegetabile; vol. 120. New York, Bronx: Published and Distributed for International Association for Plant Taxonomy by New York Botanical Garden, 1990. X, 693 p.

15. Кудрящев С.Н. Дикорастущие эфирно-масличные растения центральной части Гиссарского хребта // Труды Среднеазиат. науч.-исслед. опыт. ст. эфирно-маслич. растений О. М.П.К., 1932. Т. 1. $112 \mathrm{c}$.

16. Губанов И. А., Багдасарова Т. В., Баландина Т. П. Научное наследие выдающихся русских флористов Г.С. Карелина и И.П.Кирилова. М., 1998. 95 с.

17. Поляков П. П. Род Artemisia L. - Полынь // Флора СССР. М.; Л., 1961. Т.26. С. 425-626.

18. Филатова Н. С. Род Artemisia L. // Определитель растений Средней Азии (критический конспект флоры). СПб., 1993. Т. 10. С. 554.

19. Павлов В. Н., Губанов И. А., Барсукова А. В., Багдасарова Т. В. Гербарий Московского университета (МW). М.: Изд-во МГУ, 1978. 149 с.

20. Положий А. В., Баламова В. Ф. Типы таксонов в Гербарии им. П. Н. Крылова. Томск, 1989. 47 с.

21. Губанов И. А. Каталог типовых образцов сосудистых растений Гербария Московского университета (МW). М.: Изд-во МГУ, 1993. 160 с.

22. Губанов И.А. Каталог типовых образцов сосудистых растений Гербария Московского университета (MW). М.: Изд-во МГУ, 2002. 213 с.

\section{References}

1. Bubyreva V. A., Bialt V.V., Orlova L. V. Kollektsiia G. P. Bongarda v gerbarii kafedry botaniki SanktPeterburgskogo gosudarstvennogo universiteta (LECB) [Collection of G. P. Bongard kept in the Herbarium of Botanical department of St. Petersburg State University (LECB)]. Bot. zhurn. [Botanical Journal], 2003, vol. 88, no. 2, pp. 125-133. (In Russian)

2. Bubyreva V.A., Bialt V.V., Orlova L. V. Eduard Emmanuilovich Lindemann i ego kollektsiia v gerbarii kafedry botaniki Sankt-Peterburgskogo universiteta (LECB) [Eduard Lindemann and his collection in the Herbarium of Botanical department of St. Petersburg State University (LECB)]. Bot. zhurn. [Botanical Journal], 2003, vol. 88, no. 11, pp. 156-164. (In Russian) 
3. Bubyreva V.A. Kollektsii, khraniashchiesia v Gerbarii kafedry botaniki Sankt-Peterburgskogo gosudarstvennogo universiteta (LECB) [Collections kept in Herbarium of Botany Department of St. Petersburg State University]. Bot. zhurn. [Botanical Journal], 2004, vol. 89, no. 7, pp. 1190-1208. (In Russian)

4. Bialt V.V., Bubyreva V.A. Tipovye obraztsy, khraniashchiesia v Gerbarii Sankt-Peterburgskogo gosudarstvennogo universiteta (LECB). Chast' 1. Semeistvo Ericaceae [Specimina typica in herbario universitatis Petropolitanae (LECB) conservata. Pars 1. Familia Ericaceae]. Novosti sist. vyssh. rast. [Novitates systematicae plantarum vascularum], 2005, vol.37, pp. 208-220. (In Russian)

5. Bialt V.V., Bubyreva V.A. Tipovye obraztsy, khraniashchiesia v Gerbarii Sankt-Peterburgskogo gosudarstvennogo universiteta (LECB). Chast' 2. Semeistvo Restionaceae [Specimina typica in herbario universitatis Petropolitanae (LECB) conservata. Pars 2. Familia Restionaceae)]. Novosti sist. vyssh. rast. [Novitates systematicae plantarum vascularum], 2005, vol.37, pp. 121-227. (In Russian)

6. Bialt V.V., Bubyreva V.A. Tipovye obraztsy, khraniashchiesia v Gerbarii Sankt-Peterburgskogo gosudarstvennogo universiteta (LECB). Chast' 3. Semeistvo Oxalidaceae [Specimina typica in herbario universitatis Petropolitanae (LECB) conservata. Pars 3. Familia Oxalidaceae)]. Novosti sist. vyssh. rast. [Novitates systematicae plantarum vascularum], 2005, vol.37, pp. 228-232. (In Russian)

7. Bubyreva V.A., Bialt V.V., Orlova L.V. Tipovye obraztsy K.Vil'denova v Gerbarii SanktPeterburgskogo gosudarstvennogo universiteta (LECB) [The C. Willdenow's type specimens in the Herbarium of Saint-Petersburg State University (LECB)]. Bot. zhurn. [Botanical Journal], 2006, vol.91, no. 1, pp. 114-132. (In Russian)

8. Byalt V., Bubyreva V., Orlova L. The history of Eduard Lindemann's collection kept in the Herbarium of Botanical Department of St. Petersburg State University (LECB). Taxon, 2008, vol. 57, no. 1, pp. 275-278.

9. Bialt V.V., Bubyreva V.A. Tipovye obraztsy, khraniashchiesia v gerbarii Sankt-Peterburgskogo gosudarstvennogo universiteta (LECB). Chast' 4. Semeistvo Polygalaceae [Type specimens, deposited in the Herbarium of Saint-Petersburg State University (LECB). Part 4. Family Polygalaceae]. Vestnik of SaintPetersburg University. Series 3. Biology, 2012, issue 4, pp. 27-37. (In Russian)

10. Bialt V.V., Bubyreva V.A. Tipovye obraztsy, khraniashchiesia v Gerbarii Sankt-Peterburgskogo gosudarstvennogo universiteta (LECB). Chast' 5. Semeistvo Tamaricaceae [Type Specimens kept in Herbarium of St. Petersburg State University (LECB). Part 5. Family Tamaricaceae]. Vestnik of SaintPetersburg University. Series 3. Biology, 2014, issue 3, pp. 4-15. (In Russian)

11. Bialt V.V., Bubyreva V.A. Khraniashchiesia v SPBGU tipovye obraztsy taksonov, opisannykh V.L. Komarovym $\mathrm{v}$ studencheskie gody [Type specimens of taxa described by V.L.Komarov in student time and kept in Herbarium of St. Petersburg State University (LECB)]. Vestnik of Saint-Petersburg University. Series 3. Biology, 2014, issue 4, pp. 89-107. (In Russian)

12. Bialt V. V., Potokin A. F., Bubyreva V. A. Tipovye obraztsy sem. Annonaceae Juss., khraniashchiesia $\mathrm{v}$ gerbariiakh SPbGU (LECB) i SPbGLTU (KFTA) [Type specimens of family Annonaceae Juss. kept in herbaria of Saint-Petersburg State University (LECB) and St. Petersburg State Forest University (KFTA), St. Petersburg (Russia)]. Vestnik of Saint-Petersburg University. Series 3. Biology, 2014, issue 1, pp. 55-68. (In Russian)

13. Zhizn' rastenii [Plant Life]. Ed. by A.L. Takhtadzhian. Moscow, 1981, vol.5, part 2. 512 p. (In Russian)

14. Index Herbariorum: a guide to the location and contents of the world's public herbaria. 8th ed. Regnum vegetabile; vol. 120. New York, Bronx: Published and Distributed for International Association for Plant Taxonomy by New York Botanical Garden, 1990. X, 693 p.

15. Kudriashev S.N. Dikorastushchie efirno-maslichnye rasteniia tsentral'noi chasti Gissarskogo khrebta [Wild essential oil plants of the Central part of Hissarsky ridge]. Trudy Sredneaziat. nauch.-issled. opyt. st. efirno-maslich. rastenii O. M. P. K. [Proceedings of Central Asian research experimental station of essential oil plant of O.M.P.C.], 1932, vol.1. 112 p. (In Russian)

16. Gubanov I. A., Bagdasarova T.V., Balandina T.P. Nauchnoe nasledie vydaiushchikhsia russkikh floristov G.S. Karelina i I.P. Kirilova [Scientific heritage of outstanding Russian florists G. S. Karelin and I. P. Kirilov]. Moscow, 1998. 95 p. (In Russian)

17. Poliakov P. P. Rod Artemisia L. - Polyn' [Genus Artemisia L.]. Flora SSSR [Flora USSR]. Moscow, Leningrad, 1961, vol.26, pp. 425-626. (In Russian)

18. Filatova N. S. Rod Artemisia L. [Genus Artemisia L.]. Opredelitel' rastenii Srednei Azii (kriticheskii konspekt flory) [Conspectus Florae asiae Mediae]. St. Petersburg, 1993, vol. 10, pp. 554. (In Russian)

19. Pavlov V. N., Gubanov I. A., Barsukova A. V., Bagdasarova T. V. Gerbarii Moskovskogo universiteta (MW) [Herbarium Universitatis Mosquensis (MW)]. Moscow, MGU Publ., 1978. 149 p. (In Russian)

20. Polozhii A.V., Balashova V.F. Tipy taksonov v Gerbarii im. P.N.Krylova [Types of Taxa at Herbarium]. Tomsk, 1989. 47 p. (In Russian) 
21. Gubanov I. A. Katalog tipovykh obraztsov sosudistykh rastenii Gerbariia Moskovskogo universiteta $(M W)$ [Catalogue of authentic specimens of vascular plants of the Moscow State University Herbarium (MW)]. Moscow, MGU Publ., 1993. 160 p. (In Russian)

22. Gubanov I. A. Katalog tipovykh obraztsov sosudistykh rastenii Gerbariia Moskovskogo universiteta $(M W)$ [Catalogue of authentic specimens of vascular plants of the Moscow State University Herbarium (MW)]. Moscow, MGU Publ., 2002. 213 p. (In Russian)

Статья поступила в редакцию 6 октября, принята 25 ноября 2015 г.

Сведения об авторах:

Коробков Александр Александрович - кандидат биологических наук

Бялт Вячеслав Вячеславович - кандидат биологических наук

Бубырева Валентина Александровна - кандидат биологических наук, доцент

Korobkov Alexander A. - $\mathrm{PhD}$

Byalt Vyacheslav V. - PhD

Bubyreva Valentina A. - PhD, Associate Professor 